\title{
Engineering the translaminar fracture behaviour of thin-ply composites
}

\author{
Gianmaria Bullegas $^{\mathrm{a}, *}$, Silvestre T. Pinho ${ }^{\mathrm{a}}$, Soraia Pimenta ${ }^{\mathrm{b}}$ \\ ${ }^{a}$ Department of Aeronautics, Imperial College London, South Kensington Campus, SW7 2AZ London, United Kingdom \\ ${ }^{b}$ Department of Mechanical Engineering, Imperial College London, South Kensington Campus, SW7 2AZ London, United \\ Kingdom
}

\begin{abstract}
Bio-inspired patterns of micro-cuts perpendicular to the fibre direction in thin-ply CFRP laminates have been used to increase the translaminar fracture toughness of the material. An analytical model to predict the probability of bundle pull-out during translaminar crack propagation was developed and validated through an experimental parametric study. The model was used to design three hierarchical patterns of micro-cuts and the patterns have been tested using Compact Tension specimens. The increase in fracture toughness for the three patterns was $+15 \%,+60 \%$ and $+214 \%$ when compared with the baseline material, thereby demonstrating the potential of engineering the fracture surface in CFRPs through well-designed patterns of micro-cuts to improve the damage tolerance of the material.

Keywords: Carbon fibres, Fracture toughness, Damage tolerance, Scanning electron microscopy (SEM), Bio-inspired
\end{abstract}

\section{Introduction}

The translaminar fracture toughness of Carbon Fibre Reinforced Polymers (CFRPs), which is the fracture toughness associated with longitudinal tensile failure (involving tensile failure of the fibres), is an important material property which controls the damage initiation and propagation in the case of longitudinal loading.

5 Therefore, increasing the translaminar fracture toughness can lead to CFRP structures with improved damage resistance and damage tolerance.

Visual examination of the translaminar fracture surface of CFRP laminates (fracture surface associated with tensile failure of the fibres) reveals a hierarchical organization of fibre pull-outs, where single fibres are pulled out of small bundles, which in turn are pulled out of larger bundles [1,2]. Most authors agree that the translaminar fracture toughness in CFRPs is directly related to the energy dissipated by debonding and by friction during the formation of these hierarchical surface $[3,4,5,6,7]$. These results suggest that an increase in toughness can be achieved by controlling the morphology of these hierarchical surfaces and promoting the formation of longer bundle pull-outs.

Analogously, biological composites with hierarchical microstructures often show remarkable values of toughness when compared to their constituent phases $[8,9,10]$. In these materials, crack deflection is used to promote the formation of hierarchical pull-out geometries and achieve higher toughness $[11,12,13,14,15$, $16,17]$.

\footnotetext{
* Corresponding author

Email addresses: g.bullegas14@imperial.ac.uk (Gianmaria Bullegas), silvestre.pinho@imperial.ac.uk (Silvestre T. Pinho), soraia.pimenta@imperial.ac.uk (Soraia Pimenta)

URL: wwwf.imperial.ac.uk/aeronautics/research/pinholab (Silvestre T. Pinho), www.imperial.ac.uk/people/soraia.pimenta (Soraia Pimenta)
} 
Crack deflection is a powerful toughening mechanism also used in engineering materials. Nanoparticles are used as inclusions in polymeric materials to deviate and branch the crack propagation pattern, therefre creating more complex fracture surfaces and increasing energy dissipation [18, 19, 20]. Mirkhalaf $[21]$ demonstrated how crack deflection induced by the presence of a 3D array of laser engraved micro-cracks can be used to control the crack propagation pattern and significantly increase the toughness of glass.

The insights from modelling and experimental results in CFRP [1, 2, 7, 22, 23], and the example from natural composites $[13,14,15,16,8,9,10,12]$ indicate that there is a potential for CFRPs with an engineered toughness.

This paper explores the idea of using patterns of carefully-placed micro-cuts perpendicularly to the fibre direction to create thin-ply CFRPs with a discontinuous, yet highly ordered, micro-structure (see Figure 1). The presence of the micro-cuts is expected to change the behaviour of the composite during translaminar crack propagation, promoting the formation of large pull-out structures and increasing energy dissipation.

Thin-ply unidirectional (UD) prepregs (typically from 20 to $50 \mu \mathrm{m}$ in thickness) recently emerged as new class of materials that can potentially lead to weight reduction in composite structures. They exhibit enhanced resistance against interlaminar matrix cracking and delamination. This property results in higher un-notched tensile strength and fatigue strength when compared with standard-size prepregs [24, 25] (typically from 120 to $200 \mu \mathrm{m}$ in thickness).

However, both modelling and experimental results $[7,26]$ showed that the translaminar fracture toughness decreases significantly with the ply thickness. Thin-ply laminates with quasi-isotropic layup also exhibit a lower tensile strength in open hole tests when compared with equivalent standard-ply laminates [25, 27]. The failure modes observed in this type of tests are debonding and pull-out of the $\pm 45^{\circ}$ plies in the case of

One of the possible reasons for the higher open hole tensile strength of standard-ply laminates is the stress relaxation near the hole edge after the initial failure. Delamination tends to occur at the hole edges and contributes to lower the stress concentration. In thin-ply laminates, delamination is suppressed, so that the stresses are concentrated until catastrophic failure occurs.

Another important factor to be considered is that, since the dominant failure mode during open hole tensile tests is translaminar fracture, the lower translaminar fracture toughness of thin-ply laminates can play an important role in determining the lower ultimate strength. Improving the translaminar fracture toughness of thin-ply CFRP structures could lead to higher damage resistance and damage tolerance in the presence of rivet holes or other geometrical discontinuities. For these reasons, thin-ply composites are an ideal candidate to test the micro-structure design technique developed in this paper.

The aims of the present work are:

i to develop a manufacturing technique to create CFRP laminates with precisely-placed patterns of microcuts;

ii to design patterns of micro-cuts to cause crack deflection and promote formation of large bundle pull-outs; and

iii to validate the concept experimentally by measuring the translaminar fracture toughness of CFRP laminates with hierarchical patterns of micro-cuts using Compact Tension specimens. 


\section{Materials, manufacturing and test methods}

\subsection{Material system used}

The material system used in this work is a thin-ply UD carbon-epoxy prepreg, TR50s/K51, provided by Skyflex $[28,29]$ in two grades (which corresponds to different ply thicknesses); individual fibre and laminate properties are reported in Table 1.

\subsection{Specimens definition}

The behaviour of thin-ply composites with patterns of micro-cuts during translaminar fracture propagation was studied using Compact Tension (CT) specimens (Figure 2(a)). The specimens have a symmetric cross-ply lay-up $\left(\left[90,(0,90)_{20}\right]_{\mathrm{s}}\right)$ with forty $0^{\circ}$ plies. The thinner prepreg material (grade A in Table 1 ) is used for the $0^{\circ}$ plies, and the thicker prepreg (grade B in Table 1 ) is used for the $90^{\circ}$ plies, to guarantee better isolation of the pull-outs formation mechanisms in the different $0^{\circ}$ plies. Each $0^{\circ}$ ply contains a pattern of micro-cuts aligned with the test section of the specimen as shown in Figure 2(b). By having a different pattern in each $0^{\circ}$ ply, while keeping a symmetric lay-up, it is possible to test up to 20 different patterns in each CT specimen.

Table 1: TR50s/K51 properties [28, 29]

\begin{tabular}{lc}
\hline Single fibre properties & \\
\hline Fibre diameter $[\mu \mathrm{m}]$ & 6.82 \\
Longitudinal modulus $E_{1}^{\mathrm{f}}[\mathrm{GPa}]$ & 240 \\
Average tensile strength $X_{\mathrm{m}}^{\mathrm{f}}[\mathrm{GPa}]$ & 4.9 \\
Coefficient of Variation of strength $\mathrm{CoV}_{\mathrm{m}}^{\mathrm{f}}$ & $0.24^{a}$ \\
Reference length $\ell_{\mathrm{f}}[\mathrm{mm}]$ & 10 \\
Fracture toughness $\mathcal{G}_{\mathrm{ff}}\left[\mathrm{J} / \mathrm{m}^{2}\right]$ & $7.4^{b}$ \\
\hline Matrix properties & \\
\hline Mode-II in-situ interfacial toughness $\mathcal{G}_{\mathrm{sl}}\left[\mathrm{kJ} / \mathrm{m}^{2}\right]$ & 1 \\
Matrix shear yielding $\tau_{\mathrm{sl}}[\mathrm{MPa}]$ & 88.5 \\
In-situ frictional stress $\tau_{\mu}[\mathrm{MPa}]$ & $10{ }^{c}$ \\
\hline Laminate properties & \\
\hline Nominal ply thickness ${ }^{d}[\mathrm{~mm}]$ & $\mathrm{A}: 0.03$ \\
Fibre areal weight ${ }^{2}\left[\mathrm{~g} / \mathrm{m}^{2}\right]$ & $\mathrm{B}: 0.055$ \\
Nominal fibre volume fraction $\left[\mathrm{g} / \mathrm{cm}^{3}\right]$ & $\mathrm{B}: 50$ \\
Cured resin density $\left[\mathrm{g} / \mathrm{cm}^{3}\right]$ & 0.60 \\
Nominal fibre density $\left[\mathrm{g} / \mathrm{cm}^{3}\right]$ & 1.20 \\
Nominal laminate density $\left[\mathrm{g} / \mathrm{cm}^{3}\right]$ & 1.82 \\
\hline Longitudinal CFRP modulus $E_{1}[\mathrm{GPa}]$ & 1.60 \\
Transverse CFRP modulus $E_{2}[\mathrm{GPa}]$ & 125.3 \\
Major CFRP Poisson's ratio $\nu_{12}[\mathrm{GPa}]$ & 8.4 \\
Shear modulus $G_{12}[\mathrm{GPa}]$ & 0.28 \\
Intralaminar fracture toughness $\mathcal{G}_{\mathrm{Ic}}^{90}\left[\mathrm{~kJ} / \mathrm{m}^{2}\right]$ & 5.1 \\
\hline
\end{tabular}

\footnotetext{
${ }^{a}$ This property was back-calculated using the HFBM [30] to fit the composite tensile strength.

${ }^{b}$ As estimated by Honjo [31].

${ }^{c}$ Nominal property for carbon-epoxy systems [6].

${ }^{d}$ Two different grades (A and B) were used.

${ }^{e}$ Measured by Teixeira et al. [26].
} 
The design of the CT specimens used in this work is similar to others reported in the literature [1, 26, 32], which is derived from the ASTM E399 standard [33]; but with one important modification: the specimens contain a central notch which terminates with a blunted semicircular shape, instead of a sharp machined notch. This semicircular blunt notch overlaps with a $10 \mathrm{~mm}$ straight cut laser-engraved in each $0^{\circ}$ ply before lamination, thus terminating in a $5 \mathrm{~mm}$ long laser-cut sharp notch which acts as crack initiator during the tensile test. Since the pattern of micro-cuts and the straight cut are simultaneously realised with the same laser engraving process, this specimen design guarantees that the translaminar crack propagating from the notch will be perfectly aligned with the patterns of micro-cuts. Furthermore, the laser-cut notch is considerably sharper than those that can be achieved with other methods in the literature [34], as a tip radius of down to $\sim 7 \mu \mathrm{m}$ can be achieved with the machine used in this study.

\subsection{Laminate manufacturing}

\subsubsection{Laser cutting technique}

Laser micro-milling was used to create the patterns of micro-cuts in the $0^{\circ}$ plies via an engraving process. in the focal region, which is able to vaporize the material locally. A system of mirrors and lenses (galvo) controls the movements of the laser and ensures sub-micron precision in the position of each micro-cut.

Figure 3 shows an example of a straight cut produced in a UD thin-ply prepreg (grade A in Table 1). It is possible to notice the presence of a small heat affected zone, which extends around the cut, where the superficial resin layer has been affected by the heat. It is not possible to notice any evident defect in the un-cut portion of the fibres; nor any effect on the fibre-matrix interface in the heat affected zone.

\subsubsection{Single-ply laser engraving}

A $200 \mathrm{~mm}$ by $250 \mathrm{~mm}$ cross-ply laminate plate $\left(\left[90,(0,90)_{20}\right]_{s}\right)$ was manufactured using hand lay-up (Figure 4). Before lamination, each $0^{\circ}$ ply was separately machined and laser-engraved with 6 distinct patterns of micro-cuts, each at a different location (Figure 4(b)). Each pattern is preceded by the initial $10 \mathrm{~mm}$ straight cut (laser-cut notch, Figure 4(a)).

\subsubsection{Laminae alignment method}

Four alignment holes were also created in each ply by the laser at the same time as the patterns and the laser-cut notch. A fixture formed by a flat support plate and four metal pins was used during the lay-up process to align the holes in each ply. Since the pin-holes, patterns and laser-cut notch are realized with the precision of the laser, this technique ensures the alignment of the patterns in the final laminate.

\subsubsection{Water-jet cutting}

After curing the laminate in an autoclave in accordance to the manufacturer specification [28], a CNC water-jet machine was used to cut the plate into the specimens geometry (Figure 4(d)). The same pin-holes alignment system was used to guarantee the coincidence of the patterns of micro-cuts in the laminate plate with the test section of the corresponding CT specimen.

\subsection{Test methods}

The CT specimens were tested using an Instron load frame with a $10 \mathrm{kN}$ load cell; each specimen was loaded under displacement control at a rate of $0.5 \mathrm{~mm} / \mathrm{min}$. A video strain gauge system (Imetron) was used to measure and record the relative displacement of two target points drawn on the surface of the specimens 
(Figure 5). Using FE, it was demonstrated that the relative displacement of these two target points is practically equal to relative displacement of the load application points, which would be more difficult to measure experimentally. Load measurements were recorded via the Instron load frame and synchronized with the relative displacement of the two target points measured by the video strain gage system.

During tensile testing, the stress concentration at the end of the semicircular notch caused the opening of the laser-cut notch, which then acted as crack initiator as shown in Figure 5. The test was stopped when the cross-head displacement reached $3 \mathrm{~mm}$. At the end of each test, the specimen was wedged before unloading in order to prevent crushing of the fracture surface.

\section{Bundle pull-out probability}

\subsection{Analytical model}

Figure 6 shows a bundle of length $\ell$ and width $w$, included in a ply of thickness $t$, formed as the result of the presence of a laser micro-cut in the proximity of an approaching translaminar crack. During crack propagation, the region near the crack tip experiences high tensile stress. The tensile stress is transferred to the bundle through shear stress at its four lateral interfaces (Figure 6).

25 The stress profile in the bundle was calculated using a shear lag analysis which assumes perfectly-plastic behaviour of the matrix and a uniform tensile stress in the bundle cross section. If the strength of the bundle is sufficient to withstand this tensile stress, the bundle will survive, causing debonding of the interfaces along the fibre direction and forming a pull-out (Figure 1(b)). If the strength of the bundle is not sufficient to withstand the tensile stress, the bundle will break and the crack will propagate through its base (Figure 1(c)).

Since the strength of a bundle of fibres is a stochastic variable [35, 36, 37, 38, 30], the event of pull-out is stochastic as well and the probability of bundle pull-out $\left(\mathrm{Pr}^{\mathrm{po}}\right)$ was defined as the complement to 1 of the probability of bundle failure $\left(\operatorname{Pr}^{\mathrm{f}}\right)$ under the given stress profile. The probability of bundle failure $\operatorname{Pr}^{\mathrm{f}}$ was calculated using the Hierarchical Fibre Bundle Model (HFBM) developed by Pimenta and Pinho [30]. The complete analytical development of the model is described in Appendix A.

The model was used to define a range over which an experimental parametric study would be conducted. Using the properties in Table 1, the pull-out probability $\operatorname{Pr}^{\mathrm{po}}$ (Figure 7) can be seen to change from $100 \%$ to $0 \%$ for bundle lengths between $0.2 \leq \ell \leq 0.8 \mathrm{~mm}$, regardless of $w$ and $p$, with reference to the pattern design in Figure 8.

\subsection{Experimental parametric study}

An experimental parametric study was carried out to obtain a correlation between the geometrical parameters of the pattern of micro-cuts and the probability of formation of bundle pull-outs on the translaminar fracture surface of the CT specimens.

Each pattern tested was cut in a single ply, and consisted of a series of micro-cuts which repeats uniformly along the test section of the specimen (Figure 8). The distance between the micro-cuts in a pattern is arbitrarily set to a large value $(p=5 \cdot w)$ to avoid interactions, and the bundle thickness is fixed by the ply thickness. The geometry of the pattern is therefore defined by the two parameters $w$ and $\ell$, which determine the width and the length of the bundle pull-out, respectively.

Based on the results of the analytical model, five different values of the parameter $w$ were selected, ranging from $0.025 \mathrm{~mm}$ up to $0.5 \mathrm{~mm}$. For each value of $w$, eight different values of the parameter $\ell$ were selected, ranging from $0.025 \mathrm{~mm}$ up to $2 \mathrm{~mm}$ (Figure 7). Therefore, 40 different patterns were defined (Table 2). 
Table 2: Combinations of values of $w$ and $\ell$ used in the parametric study

\begin{tabular}{|c|c|c|c|c|c|c|c|c|}
\hline \multicolumn{9}{|c|}{ Patterns } \\
\hline$w[\mathrm{~mm}]$ & \multicolumn{8}{|c|}{$\ell[\mathrm{mm}]$} \\
\hline 0.025 & 0.025 & 0.05 & 0.075 & 0.1 & 0.125 & 0.15 & 0.175 & 0.2 \\
\hline 0.05 & 0.05 & 0.1 & 0.15 & 0.2 & 0.25 & 0.3 & 0.35 & 0.375 \\
\hline 0.1 & 0.1 & 0.2 & 0.3 & 0.4 & 0.5 & 0.55 & 0.6 & 0.65 \\
\hline 0.2 & 0.2 & 0.4 & 0.6 & 0.7 & 0.8 & 0.9 & 1.0 & 1.1 \\
\hline 0.5 & 0.25 & 0.5 & 0.75 & 1.0 & 1.25 & 1.5 & 1.75 & 2.0 \\
\hline Specimens & \multicolumn{4}{|c|}{ SP1 \& SP3 } & \multicolumn{4}{|c|}{ SP2 } \\
\hline
\end{tabular}

Three CT specimens were used in this experimental study (SP1 to SP3 in Table 2); the dimensions and orientation of the CT specimens are described in Figure 2. Each specimen is formed by a cross-ply laminate with forty $0^{\circ}$ plies; therefore, it is possible to test 20 different patterns of micro-cuts disposed in symmetrical position across the lay-up in each specimen. The distribution of the 40 patterns in the three CT specimens is defined in Table 2 .

In order to assess possible interactions of patterns in neighbouring $0^{\circ}$ plies, specimen SP1 and SP3 contain the same 20 patterns, but placed in a different position across the lay-up. In this way, an eventual dependency of the pull-out probability on the lay-up sequence could be identified. In specimen SP1, the length $\ell$ of the pattern in a specific layup position is defined by following Table 2 row by row (from column 2 to 5 ), while the length $\ell$ of the pattern in equivalent layup positions in specimens SP3 follows the order of Table 2 column by column (from column 2 to 5 ). The distribution of patterns in specimen SP2 also follows Table 2 row by row (from column 6 to 9 ). The corresponding value of $w$ for every pattern is always defined in column 1 of Table 2 .

\subsection{Results of the parametric study}

Figure 9(a) shows the fracture surface of specimen SP1 away from the laser notch. It is possible to notice large bundle pull-outs corresponding to the positions of the micro-cuts in the $0^{\circ}$ plies. These large bundle pull-outs are not disposed uniformly on the surface. In fact, there are $0^{\circ}$ plies with a regular sequence of pull-outs and others where the bundle pull-outs are more sparse or not present at all. The latter indicates bundle failure Figure 1(c) for the particular pattern in that ply.

A statistical analysis of the fracture surfaces was performed in order to correlate the geometrical parameters of the patterns of micro-cuts and the bundle pull-out probability. For each pattern, the number of bundle pull-outs (as opposed to bundle failures) was counted based on the SEM observation of the entire fracture surface and divided by the total number of micro-cuts in the pattern to obtain the experimental pull-out probability. The results of this statistical analysis are shown in Figure 10, and are compared against the initial modelling predictions.

Note that each $0^{\circ}$ ply was engraved with a pattern of micro-cuts with specific values of $w$ and $\ell$. Each specimen contains the same pattern twice in symmetrical position across the lay-up. Therefore, each experimental symbol in Figure 10 is the average of bundle pull-outs in two plies. Furthermore, specimen SP3 (hollow symbols) contained the same patterns as specimen SP1 (full symbols) but in different position across the lay-up. 


\section{CFRP composites with hierarchical micro-structure}

\subsection{Hierarchical micro-structure design}

Following the successful generation of bundle pull-outs during the parametric study, we then proceeded to design micro-structural patterns aimed at achieving laminates with higher values of translaminar toughness. Figure 11 shows the three pattern designs used in this study. These patterns exploit the idea of using a micro-cut to produce a large bundle pull-out and scale it hierarchically from 1 to 3 levels of hierarchy. Each pattern was used for all $0^{\circ}$ plies of a specific specimen.

The single micro-cut length $w$ was chosen equal to $0.03 \mathrm{~mm}$ for all patterns. An inter-space $p=0.03 \mathrm{~mm}$ was left between the cuts. The pull-out lengths for each hierarchical level were chosen considering the results of the pull-out probability model (which proved to correlate well with the experimental results in Figure 10), in order to guarantee high probability of bundle pull-out (close to 100\%) while dissipating a large amount of energy during the pull-out process. Table 3 shows the geometrical parameters of each pattern.

The translaminar fracture toughness for the three different pattern designs was predicted considering the energy necessary to fracture the fibres in the inter-space during the bundle formation, plus the energy dissipated by debonding and friction during the bundle pull-out process. The analytical development of the model for a hierarchical structure of bundle pull-outs with $n$ levels of hierarchy is described in Appendix B. The values of translaminar fracture toughness expected for the three patterns (H1, H2 and H3) as a function of the bundle length $\ell$ are shown in Figure 12.

\subsection{Translaminar toughness tests}

A total of four CT specimens were used in this experimental study. One CT specimen (SP4) was defined without any pattern of micro-cuts so that it could be used as a baseline reference for the translaminar fracture toughness of the material. The other three CT specimens (SP5-SP7) contain the 3 hierarchical pattern designs as defined in Table 3.

The dimensions, lay-up and materials used to manufacture the CT specimens are identical to those used in the parametric study in Section 2.2. In each specimen, all $0^{\circ}$ plies were laser-engraved with the same pattern of micro-cuts. The pattern was repeated regularly along the entire length of the specimen and aligned with the test section. Accordingly, the experimental set-up and test procedure used for these tests were the same as those described in Section 2.4.

The modified compliance calibrated method $[1,2]$ was used to calculate the fracture toughness of the laminate for each specimen. The rule of mixtures was applied to calculate the translaminar toughness of the $0^{\circ}$ plies, given the toughness of the laminate measured in the experiments and the intralaminar toughness of the $90^{\circ}$ plies given in Table 1 .

Table 3: Geometrical parameters of the hierarchical patterns of micro-cuts

\begin{tabular}{|c|c|c|c|c|c|c|}
\hline \multirow[t]{2}{*}{ Specimen } & \multirow[t]{2}{*}{ Pattern } & \multicolumn{5}{|c|}{ geometrical parameters $[\mathrm{mm}]$} \\
\hline & & $w$ & $p$ & $\ell_{1}$ & $\ell_{2}$ & $\ell_{3}$ \\
\hline $\mathrm{SP} 4$ & Baseline & - & - & - & - & - \\
\hline SP5 & H1 & 0.03 & 0.03 & 0.2 & - & - \\
\hline SP6 & $\mathrm{H} 2$ & 0.03 & 0.03 & 0.2 & 0.2 & - \\
\hline SP7 & H3 & 0.03 & 0.03 & 0.3 & 0.3 & 0.3 \\
\hline
\end{tabular}




\subsection{Results of translaminar toughness tests}

Load vs. opening displacement (relative displacement of the two load application points) and translaminar the $90^{\circ}$ plies.

\section{Discussion}

\subsection{Laser engraving technique}

240

The laser engraving process used in this work created patterns of micro-cuts with typical cut thickness of $15 \mu \mathrm{m}$. Although micro-cuts images obtained via optical microscope and SEM (Figure 3) show the presence of a heat affected zone around the cut as a result of the laser-cut process, no sign of damage to the fibres was noticeable; nor any effect on the fibre-matrix interface in the heat affected zone.

Table 4: Results of the CT test for the four specimens and comparison with modelling predictions of the translaminar fracture toughness of the $0^{\circ}$ plies. $\Delta \mathcal{G}_{\text {Ic }}$ is the increase in propagation fracture toughness with respect to the baseline material/specimen.

\begin{tabular}{|c|c|c|c|c|c|c|}
\hline Pattern & $\begin{array}{l}P_{\max } \\
(\mathrm{kN}) \\
\end{array}$ & $\begin{array}{l}\mathcal{G}_{\mathrm{Ic}}^{0 ; \text { init }} \\
\left(\mathrm{kJ} / \mathrm{m}^{2}\right)\end{array}$ & $\begin{array}{l}\mathcal{G}_{\mathrm{Ic}}^{0 ; \text { prop }} \\
\left(\mathrm{kJ} / \mathrm{m}^{2}\right)\end{array}$ & $\begin{array}{l}\Delta \mathcal{G}_{\text {Ic }} \\
\%\end{array}$ & $\begin{array}{l}\mathcal{G}_{\mathrm{Ic}_{\text {mode }}}^{0} \\
\left(\mathrm{~kJ} / \mathrm{m}^{2}\right)\end{array}$ & $\begin{array}{l}\text { predictions erro } \\
\%\end{array}$ \\
\hline Baseline & 0.92 & 29.5 & 32.2 & - & - & - \\
\hline H1 & 0.89 & 31.0 & 37.0 & +15 & 40.0 & +8 \\
\hline $\mathrm{H} 2$ & 1.08 & 43.3 & 51.2 & +60 & 53.3 & +4 \\
\hline H3 & 1.58 & 101.1 & - & $>214$ & 165.0 & - \\
\hline
\end{tabular}


In conclusion, the laser engraving process allows very good precision in creating the micro-cuts and does not significantly damage the surrounding material. Therefore, it is suitable for creating CFRP laminates with hierarchical patterns of micro-cuts, or other micro-structural features.

\subsection{Lay-up process}

The fracture surfaces in Figure 14 show excellent precision in the alignment of the patterns of micro-cuts and the laser-cut notch in each $0^{\circ}$ ply with the test section of the CT specimen. Therefore, the alignment technique proved successful. This was possible due to the simultaneous laser engraving of the patterns of micro-cuts, the laser-cut notch and the alignment holes, as well as the use of the corresponding alignment fixture during the lay-up of the panel and the water-jet cutting process.

\subsection{Bundle pull-out probability}

The results of the experimental parametric study in Figure 10 clearly show a dependency of the pull-out probability on the bundle length for all patterns tested. Although differences in pull-out probability between corresponding patterns in specimens SP1 and SP3 are present (in particular for $w=0.1 \mathrm{~mm}, 0.2 \mathrm{~mm}$ and $0.5 \mathrm{~mm}$ ), these are not deemed to be significant considering the steep gradient of the pull-out probability function in the corresponding parts of the graph. Therefore, these results suggest that the position of the pattern in the lay-up did not influence the pull-out probability.

Furthermore, there was no significant difference in the pull-out probability of bundles with different widths $w$, and the experimental results correlate well with model predictions (which assume a square bundle of dimensions $w=t=0.03 \mathrm{~mm}$ ). This justifies the assumption made in the model (see Appendix A) that, in the presence of a notch and a strong stress gradient, it is not the total area of the bundle that determines the probability of pull-out, but rather the area of the sub-bundle with area $t^{2}$ that is closer to the crack tip. Since only one specimen was tested for each configuration, these experimental results do not account for eventual variability of the manufacturing process.

The good agreement between the analytical pull-out probability model and the experimental parametric study, and the success of the hierarchical pattern designs, confirm that the model developed in this paper is suitable to design hierarchical micro-structures to exploit crack deflection in CFRP laminates. Furthermore, these results also indirectly confirm the accuracy of the HFBM [30] in predicting the failure probability of bundles of fibres with different sizes.

\subsection{Hierarchical micro-structure design}

The translaminar fracture surfaces of specimens SP5 and SP6 shown in Figure 14(b) and (c) demonstrate that the patterns $\mathrm{H} 1$ and $\mathrm{H} 2$ succeed in producing hierarchical bundles of micro-cuts over the entire fracture surface of the specimens when compared with the baseline material (specimen SP4). The formation of these hierarchical structures of pull-outs completely changed the mechanical response of the specimen, which went from unstable crack propagation (Baseline material in Figure 13(a)) to stable crack propagation (Patterns H1 and H2 in Figure 13(a)) with a correspondent increase in translaminar fracture toughness.

The increase in fracture toughness for patterns $\mathrm{H} 1$ and $\mathrm{H} 2$ is in good agreement with the prediction of the analytical model which accounts for the energy necessary to fracture the fibres in the inter-space between the cuts, plus the energy dissipated by debonding and friction during the bundle pull-out process. This shows that the increase in toughness measured during the tests is due to the additional energy dissipated during the formation of the hierarchical structures of pull-outs, and other failure mechanisms such as delamination did not play a relevant role. In conclusions, the hierarchical patterns $\mathrm{H} 1$ and $\mathrm{H} 2$ behaved as designed and 
were effective in increasing the translaminar fracture toughness of the baseline material. Only one specimen was tested for each configuration; while this is sufficient to demonstrate the magnitude of the increase in toughness possible with this approach, more test repetitions would be needed to quantify in a statistically significant way the exact increase in toughness for any specific pattern.

Regarding pattern H3, the features of the fracture surface and the test data shown in Figure 14(d) and Figure 13 indicate the following sequence of events:

- the crack initially propagated on the plane defined by the laser-cut notch, producing the pull-out of two lines of hierarchical bundles and determining the rising effect in the toughness curve;

- the consequent increase in the load necessary to continue crack propagation led to tensile failure in the $90^{\circ}$ plies and consequent propagation of the crack to a region of the specimens without pattern of micro-cuts;

- the lower translaminar toughness of the baseline material in this region of the specimen led to catastrophic failure of the specimen.

It is plausible that, if the pattern of micro-cuts were repeated in the entire specimen rather than just in the test section, the crack could have reached a steady state propagation state. Accordingly, the toughness curve would have reached a constant value corresponding to the toughness propagation value, but more tests would be necessary to demonstrate this conclusion. This explanation has two main implications:

- specimen SP7 showed a shortcoming in the design of the CT specimen, rather than a failure of the micro-structure design defined by pattern H3;

- the maximum toughness values obtained from the test are for initiation and cannot be compared directly with the toughness model because the final propagation value for the pattern $\mathrm{H} 3$ is expected to be higher that the one measured.

Furthermore, the un-notched tensile strength of a quasi-isotropic laminate containing the pattern $\mathrm{H} 3$ micro-cuts design was measured experimentally and was found to be $12 \%$ lower than the strength of a laminate made of the baseline un-modified material (Appendix C). The same pattern led to a $70 \%$ increase in the maximum tensile load and $214 \%$ increase in the initiation value of translaminar fracture toughness measured during the CT tests (Section 4.3). In conclusion, the micro-structure design defined by pattern $\mathrm{H} 3$ achieved a significant increase of performances over the baseline material in a notch test scenario, while retaining most of the strength of the baseline material in a un-notched test scenario.

\section{Conclusions}

This paper has investigated the concept of using patterns of micro-cuts perpendicular to the fibre direction to create large bundle pull-outs and therefore increasing the translaminar fracture toughness of CFRP laminates. The following conclusions can be reached:

- it is possible, using hierarchical patterns of micro-cuts, to increase the translaminar fracture toughness significantly, without compromising the un-notched tensile strength of the material. The $214 \%$ increase in initiation toughness achieved in this study does not appear to be close to the actual limit for this technique; 
- the alignment methodology developed in this study enables precisions of the order of $1 \mu \mathrm{m}$ in the positioning of the individual plies during lay-up;

- the notch tip manufacturing methodology developed in this study leads to the sharpest translaminar notches in the literature, with a tip radius of $\sim 7 \mu \mathrm{m}$;

- the analytical model for predicting the probability of bundle pull-out was successful over a wide range of variation of micro-structure parameters, and proved to be a useful tool in guiding the design of hierarchical patterns of micro-cuts to increase translaminar fracture toughness.

\section{Acknowledgements}

The first authors are grateful to the funding from EPSRC under grant EP/M002500/1. The third author acknowledges the support from the Royal Academy of Engineering for her Research Fellowship on Multiscale discontinuous composites for large scale and sustainable structural applications (20152019). The authors are also grateful to Steve Harrison from Triple-H Composites for supplying the prepreg material used in this study.

\section{Appendix A Model for predicting bundle pull-out probability}

Figure 6 represents a bundle of length $\ell$ and width $w$, in a ply of thickness $t$ under tensile stress. Shear-lag analysis can be used to calculate the stress profile in the bundle. This analysis assumes a uniform distribution of tensile stress across the bundle section and a perfectly-plastic behaviour of the matrix. The fibre stress is nil at the top of the bundle (i.e. location of the micro-cut) and varies linearly along the length of the bundle:

$$
\sigma(x)=\frac{C_{\mathrm{b}} \cdot \tau_{\mathrm{sl}}}{A_{\mathrm{f}}} \cdot x \Rightarrow \sigma_{\max }=\frac{C_{\mathrm{b}} \cdot \tau_{\mathrm{sl}}}{A_{\mathrm{f}}} \cdot \ell=\lambda \cdot \ell,
$$

where $C_{\mathrm{b}}=2 \cdot(w+t)$ is the external perimeter of the bundle, $A_{\mathrm{f}}=V_{\mathrm{f}} \cdot w \cdot t$ is the total cross-section area of the fibres in the bundle, $\tau_{\mathrm{sl}}$ is the shear strength of the matrix and $V_{\mathrm{f}}$ is the fibre volume fraction.

The condition for the formation of a bundle pull-out is that the strength of the bundle has to be sufficient to withstand the linear stress distribution described by Equation (1). The strength of a bundle is a stochastic variable, therefore the probability of bundle pull-out (for a bundle of length $\ell$, width $w$ and thickness $t$ ) can be defined as

$$
\operatorname{Pr}^{\mathrm{po}}(\ell, w, t)=S_{n_{\mathrm{f}}, \ell}^{\mathrm{L}}\left(\sigma_{\max }\right),
$$

where $S_{n_{\mathrm{f}}, \ell}^{\mathrm{L}}\left(\sigma_{\max }\right)$ is the survival probability of a bundle of length $\ell$ with $n_{\mathrm{f}}$ fibres under a linear (superscript $\mathrm{L})$ stress distribution and is a function of the maximum stress $\sigma_{\max }$. The number of exposed fibres in the bundle can be calculated as $n_{\mathrm{f}}=\frac{4 \cdot A_{\mathrm{f}}^{\prime}}{\pi \cdot \phi_{\mathrm{f}}}$, where $\phi_{\mathrm{f}}$ is the single fibre diameter, and $A_{\mathrm{f}}^{\prime}=V_{\mathrm{f}} \cdot t \cdot \min \{t, w\}$. This assumes that, in the presence of a notch and a strong stress gradient, the strength of the bundle is determined by the number of fibres contained in a square bundle closer to the notch rather than by the number of fibres in the entire area of the bundle (if $w>t$ ). 
The survival probability $S_{n_{\mathrm{f}}, \ell}^{\mathrm{L}}\left(\sigma_{\max }\right)$ can be calculated using the generalized WLT [30] as

$$
\ln \left[S_{n_{\mathrm{f}}, \ell}^{\mathrm{L}}\left(\sigma_{\max }\right)\right]=\frac{1}{\sigma_{\max }} \int_{0}^{\sigma_{\max }} \frac{\ell}{\ell_{\mathrm{r}}} \cdot \ln \left[S_{n_{\mathrm{f}}, \ell_{\mathrm{r}}}^{\mathrm{U}}(\sigma)\right] \mathrm{d} \sigma,
$$

where $S_{n_{\mathrm{f}}, \ell_{\mathrm{r}}}^{\mathrm{U}}(\sigma)$ is the survival probability of a bundle of reference length $\ell_{\mathrm{r}}$ with $n_{\mathrm{f}}$ fibres under uniform stress distribution (superscript U) and can either be calculated from constituent properties using the HFBM developed by Pimenta and Pinho [30] or measured experimentally. By substituting Equation (2) in Equation (3) and after algebraic manipulation, it is possible to obtain the following expression for the probability of bundle pull-out:

$$
\ln \left[\operatorname{Pr}^{\mathrm{po}}(\ell, w, t)\right]=\frac{1}{\ell_{\mathrm{r}} \lambda} \int_{0}^{\sigma_{\max }} \ln \left[S_{n_{\mathrm{f}}, \ell_{\mathrm{r}}^{\mathrm{U}}}(\sigma)\right] \mathrm{d} \sigma,
$$

where $\lambda$ is defined in Equation (1).

\section{Appendix B Translaminar fracture toughness model}

Figure 15 shows a schematic representation of a two levels hierarchical bundle being pulled out of the fracture surface. $C_{[i]}$ and $A_{[i]}$ are the perimeter and area of the cross section of the level- $[i]$ pull-out respectively, and $\ell_{[i]}$ is the level- $[i]$ pull-out length. $P(x)$ is the pull-out force which is equal to the total friction force acting on the lateral surface of the bundle and is a function of the pull-out coordinate $x$. The expression for $P(x)$ changes during the pull-out process, depending on which surfaces of the bundle are in contact with the rest of the ply. Assuming that $\ell_{1} \leq \ell_{2}$, it is possible to write $P(x)$ as

$$
P(x)= \begin{cases}P_{\mathrm{a}}(x)=\tau_{\mu} \cdot\left[2 \cdot B_{1} \cdot \ell_{1}+C_{2} \cdot\left(\ell_{2}-x\right)+2 \cdot t \cdot\left(\ell_{1}-x\right)\right], & \text { if } x \leq \ell_{1} ; \\ P_{\mathrm{b}}(x)=\tau_{\mu} \cdot\left[2 \cdot B_{1} \cdot \ell_{1}+C_{2} \cdot\left(\ell_{2}-x\right)\right], & \text { if } \ell_{1}<x \leq \ell_{2} ; \\ P_{\mathrm{c}}(x)=\tau_{\mu} \cdot 2 \cdot B_{1} \cdot\left(\ell_{1}+\ell_{2}-x\right), & \text { if } \ell_{2}<x \leq \ell_{1}+\ell_{2} \\ 0, & \text { if } x>\ell_{1}+\ell_{2} ;\end{cases}
$$

where $\tau_{\mu}$ is the in-situ frictional stress of the matrix as given in Table 1 , and

$$
\left\{\begin{array} { l } 
{ B _ { 1 } = ( w + p ) ; } \\
{ C _ { 1 } = 2 \cdot ( B _ { 1 } + t ) ; } \\
{ A _ { 1 } = B _ { 1 } \cdot t ; }
\end{array} \quad \text { and } \quad \left\{\begin{array}{l}
B_{2}=3 \cdot(w+p) ; \\
C_{2}=2 \cdot\left(B_{2}+t\right) ; \\
A_{2}=B_{2} \cdot t .
\end{array}\right.\right.
$$

Analogous expressions could be derived for the case of $\ell_{1} \geq \ell_{2}$.

The energy necessary for the bundle formation is the sum of the energy necessary to fracture the fibres in the inter-space $p$ between the micro-cuts (hereby indicated by the subscript ' $\mathrm{ff}$ '), plus the energy dissipated by debonding and friction during the pull-out process (subscripts 'deb' and 'fric'). These three components can be calculated as

$$
\left\{\begin{array}{l}
\mathcal{W}_{\mathrm{ff}}=3 \cdot p \cdot t \cdot \mathcal{G}_{\mathrm{ff}} \\
\mathcal{W}_{\mathrm{deb}}=\left(C_{1} \cdot \ell_{1}+C_{2} \cdot \ell_{2}\right) \cdot \mathcal{G}_{\mathrm{sl}} \\
\mathcal{W}_{\text {fric }}=\int_{0}^{\ell_{1}+\ell_{2}} P \cdot \mathrm{d} x=\int_{0}^{\ell_{1}} P_{\mathrm{a}} \cdot \mathrm{d} x+\int_{\ell_{1}}^{\ell_{2}} P_{\mathrm{b}} \cdot \mathrm{d} x+\int_{\ell_{2}}^{\ell_{1}+\ell_{2}} P_{\mathrm{c}} \cdot \mathrm{d} x \\
=\tau_{\mu} \cdot\left(\frac{1}{2} \cdot C_{1} \cdot \ell_{1}^{2}+\frac{1}{2} \cdot C_{2} \cdot \ell_{2}^{2}+2 \cdot B_{1} \cdot \ell_{1} \cdot \ell_{2}\right)
\end{array}\right.
$$


where $\mathcal{G}_{\mathrm{ff}}$ is the fracture energy of the fibres and $\mathcal{G}_{\mathrm{sl}}$ is the in-situ interfacial toughness of the matrix given in Table 1. The translaminar fracture toughness for the ply $\left(\mathcal{G}_{\mathrm{Ic}}^{\mathrm{ply}}\right)$ can then be calculated as

$$
\mathcal{G}_{\mathrm{Ic}}^{\mathrm{ply}}=\frac{\mathcal{W}_{\mathrm{ff}}+\mathcal{W}_{\mathrm{deb}}+\mathcal{W}_{\text {fric }}}{A_{2}}
$$

It is possible to extend the same approach to a bundle pull-out with $[n]$ levels of hierarchy:

$$
\left\{\begin{array}{l}
\mathcal{W}_{\mathrm{ff}}=(2 \cdot n-1) \cdot p \cdot t \cdot \mathcal{G}_{\mathrm{ff}} \\
\mathcal{W}_{\mathrm{deb}}=\sum_{[i]=1}^{n}\left(C_{[i]} \cdot \ell_{[i]}\right) \cdot \mathcal{G}_{\mathrm{sl}} ; \\
\mathcal{W}_{\mathrm{fric}}=\tau_{\mu} \cdot\left(\frac{1}{2} \cdot \sum_{[i]=1}^{n} C_{[i]} \cdot \ell_{[i]}^{2}+2 \cdot \sum_{[i]=1}^{n} B_{[i]} \cdot \ell_{[i]} \cdot\left(\sum_{[k]=i+1}^{n} \ell_{[k]}\right)\right)
\end{array}\right.
$$

where

$$
\left\{\begin{aligned}
B_{[i]} & =(2 \cdot i-1) \cdot(w+p) \\
C_{[i]} & =2 \cdot\left(B_{[i]}+t\right) \\
A_{[i]} & =B_{[i]} \cdot t
\end{aligned}\right.
$$

Accordingly, the translaminar fracture toughness for $[n]$ hierarchical levels can be written as

$$
\mathcal{G}_{\mathrm{Ic}}^{\text {ply }}=\frac{\mathcal{W}_{\mathrm{ff}}+\mathcal{W}_{\text {deb }}+\mathcal{W}_{\text {fric }}}{A_{[n]}}
$$

It is worth noting that the contribution of the fibre failure in the expression above is in general not very significant for carbon-fibre systems; but might be important for other material systems.

\section{Appendix C Un-notched tensile tests}

Tensile tests were carried out to measure the un-notched tensile strength of thin-ply laminates with hierarchical patterns of micro-cuts. The specimens configuration is shown in Figure 16(a). The specimens had a quasi-isotropic lay-up (lay-up sequence $[45,90,-45,0]_{5 s}$ ), and were manufactured from the grade A Skyflex UD prepreg (Table 1) using the same laser engraving and lay-up procedures described in Section 2.3. Glass fibre tabs were glued to the specimens to reduce gripping damage.

A total of ten specimens were used for this study: five specimens were manufacture using the baseline material without any pattern of micro-cuts; while the other five were manufacture using the modified material with the pattern H3 (Figure 11(c)). For the five specimens with the pattern of micro-cuts, each ply in the laminate was laser engraved before lamination in a region correspondent to the central portion of the the specimen (pattern region in Figure 16(a)). The pattern of micro-cuts was oriented perpendicularly to the fibre direction in each ply and was repeated over the entire region with a period of $0.9 \mathrm{~mm}$ between each row of micro-cuts.

The specimens were tested using an Instron load frame equipped with a $50 \mathrm{kN}$ load cell. The tests were carried out in displacement control $(5 \mathrm{~mm} / \mathrm{min})$ and were interrupted after complete failure of the specimen.

The average strengths and standard deviations for the two specimen configurations tested can be found in Figure 16(b). The specimens with hierarchical patterns of micro-cuts show only a $12 \%$ reduction in unnotched strength and a significantly lower standard deviation when compared with the baseline material. Note that the $12 \%$ decrease in un-notched strength was determined by the same pattern of micro-cuts that led to a $70 \%$ increase in the maximum tensile load measured during the CT tests (Section 4.3). 


\section{References}

[1] S. Pinho, P. Robinson, L. Iannucci, Fracture toughness of the tensile and compressive fibre failure modes in laminated composites, Composites Science and Technology 66 (2006) 2069-2079.

[2] M. Laffan, S. Pinho, P. Robinson, L. Iannucci, Measurement of the in situ ply fracture toughness associated with mode I fibre tensile failure in FRP. part I: Data reduction, Composites Science and Technology 70 (2010) 606-613.

[3] Y.-C. Gao, Y.-W. Mai, B. Cotterell, Fracture of fiber-reinforced materials, ZAMP Zeitschrift fr angewandte Mathematik und Physik 39 (1988) 550-572.

[4] J. Wells, P. Beaumont, Debonding and pull-out processes in fibrous composites, Journal of Materials Science 20 (1985) 1275-1284.

[5] J.-K. Kim, Y.-w. Mai, High strength, high fracture toughness fibre composites with interface control-a review, Composites Science and Technology 41 (1991) 333-378.

[6] K. A, Interface effects and the work of fracture of a vibrous composite, Proc Roy Soc Ser A Math Phys Sci 319 (1970) 95-116.

[7] S. Pimenta, S. Pinho, An analytical model for the translaminar fracture toughness of fibre composites with stochastic quasi-fractal fracture surfaces, Journal of the Mechanics and Physics of Solids 66 (2014) 78-102.

[8] J.-Y. Rho, L. Kuhn-Spearing, P. Zioupos, Mechanical properties and the hierarchical structure of bone, Medical Engineering and Physics 20 (1998) 92-102.

[9] R. Nalla, J. Kinney, R. Ritchie, Mechanistic fracture criteria for the failure of human cortical bone, Nature Materials 2 (2003) 164-168.

[10] M. Yahyazadehfar, D. Bajaj, D. Arola, Hidden contributions of the enamel rods on the fracture resistance of human teeth, Acta Biomaterialia 9 (2013) 4806-4814.

[11] H. Peterlik, P. Roschger, K. Klaushofer, P. Fratzl, From brittle to ductile fracture of bone, Nature Materials 5 (2006) 52-55.

[12] A. K. Dastjerdi, R. Rabiei, F. Barthelat, The weak interfaces within tough natural composites: Experiments on three types of nacre, Journal of the Mechanical Behavior of Biomedical Materials 19 (2013) $50-60$.

[13] S. Kamat, X. Su, R. Ballarini, A. Heuer, Structural basis for the fracture toughness of the shell of the conch strombus gigas, Nature 405 (2000) 1036-1040.

[14] R. Menig, M. Meyers, M. Meyers, K. Vecchio, Quasi-static and dynamic mechanical response of haliotis rufescens (abalone) shells, Acta Materialia 48 (2000) 2383-2398.

[15] A. P. Jackson, J. F. V. Vincent, R. M. Turner, The mechanical design of nacre, Proceedings of the Royal Society of London B: Biological Sciences 234 (1988) 415-440.

[16] I. Jager, P. Fratzl, Mineralized collagen fibrils: A mechanical model with a staggered arrangement of mineral particles, Biophysical Journal 79 (2000) 1737-1746. 
[17] H. Gao, Application of fracture mechanics concepts to hierarchical biomechanics of bone and bone-like materials, International Journal of Fracture 138 (2006) 101-137.

[18] B. Johnsen, A. Kinloch, R. Mohammed, A. Taylor, S. Sprenger, Toughening mechanisms of nanoparticlemodified epoxy polymers, Polymer 48 (2007) 530-541.

[19] R. Pearson, A. Yee, Influence of particle size and particle size distribution on toughening mechanisms in rubber-modified epoxies, Journal of Materials Science 26 (1991) 3828-3844.

[20] B. Wetzel, P. Rosso, F. Haupert, K. Friedrich, Epoxy nanocomposites - fracture and toughening mechanisms, Engineering Fracture Mechanics 73 (2006) 2375-2398.

[21] M. Mirkhalaf, A. Dastjerdi, F. Barthelat, Overcoming the brittleness of glass through bio-inspiration and micro-architecture, Nature Communications 5 (2014).

[22] G. Bullegas, S. Pinho, S. Pimenta, Improving translaminar toughness of thin-ply laminates., Comptest, 7th International Conference on Composites Testing and Model Identification (2015).

[23] G. Bullegas, S. Pinho, S. Pimenta, Bioinspired microstrucutre design to improve translaminar fracture toughness of thin-ply composites., ICCM, 20th International Conferences on Composite Materials (2015).

[24] T. Yokozeki, Y. Aoki, T. Ogasawara, Experimental characterization of strength and damage resistance properties of thin-ply carbon fiber/toughened epoxy laminates, Composite Structures 82 (2008) 382-389.

[25] S. Sihn, R. Kim, K. Kawabe, S. Tsai, Experimental studies of thin-ply laminated composites, Composites Science and Technology 67 (2007) 996-1008.

[26] R. F. Teixeira, S. T. . Pinho, P. Robinson, Thickness-dependence of the translaminar fracture toughness: experimental study using thin-ply composites, Composites Science and Technology, accepted for pubblication (2015).

[27] M. Wisnom, S. Hallett, C. Soutis, Scaling effects in notched composites, Journal of Composite Materials 44 (2010) 195-210.

[28] Skyflex, K51 epoxy prepreg, Technical datasheet, 2013.

[29] C. Mitsubishi Rayon, Pyrofil tr50s, Technical datasheet, 2013.

[30] S. Pimenta, S. Pinho, Hierarchical scaling law for the strength of composite fibre bundles, Journal of the Mechanics and Physics of Solids 61 (2013) 1337-1356.

[31] K. Honjo, Fracture toughness of pan-based carbon fibers estimated from strength-mirror size relation, Carbon 41 (2003) $979-984$.

[32] A. Bergan, C. Dvila, F. Leone, J. Awerbuch, T.-M. Tan, A mode I cohesive law characterization procedure for through-the-thickness crack propagation in composite laminates, Composites Part B: Engineering 94 (2016) 338-349.

[33] ASTM E399-12e3 Standard Test Method for LinearElastic Planestrain Fracture Toughness KIc of Metallic Materials, ASTM International, West Conshohocken, PA, 2012. 
[34] M. Laffan, S. Pinho, P. Robinson, A. McMillan, Translaminar fracture toughness: The critical notch tip radius of 0 plies in CFRP, Composites Science and Technology 72 (2011) 97-102.

[35] H. E. Daniels, The statistical theory of the strength of bundles of threads I, Mathematical and Physical Sciences 183 (1945) 405-435.

[36] B. W. Rosen, Tensile failure of fibrous composites, AIAA JOURNAL 2 (1964) 1985-1991.

455

[37] I. J. Beyerlin, S. L. Phoenix, Statistics of fracture for an elastic notched composite lamina containing weibull fibers part I. features from monte-carlo simulation, Engineering Fracture Mechanics 57 (1997) $241-265$.

[38] I. J. Beyerlin, S. L. Phoenix, Statistics of fracture for an elastic notched composite lamina containing weibull fibers part II. probability models of crack growth, Engineering Fracture Mechanics 57 (1997) $267-299$. 
(a)

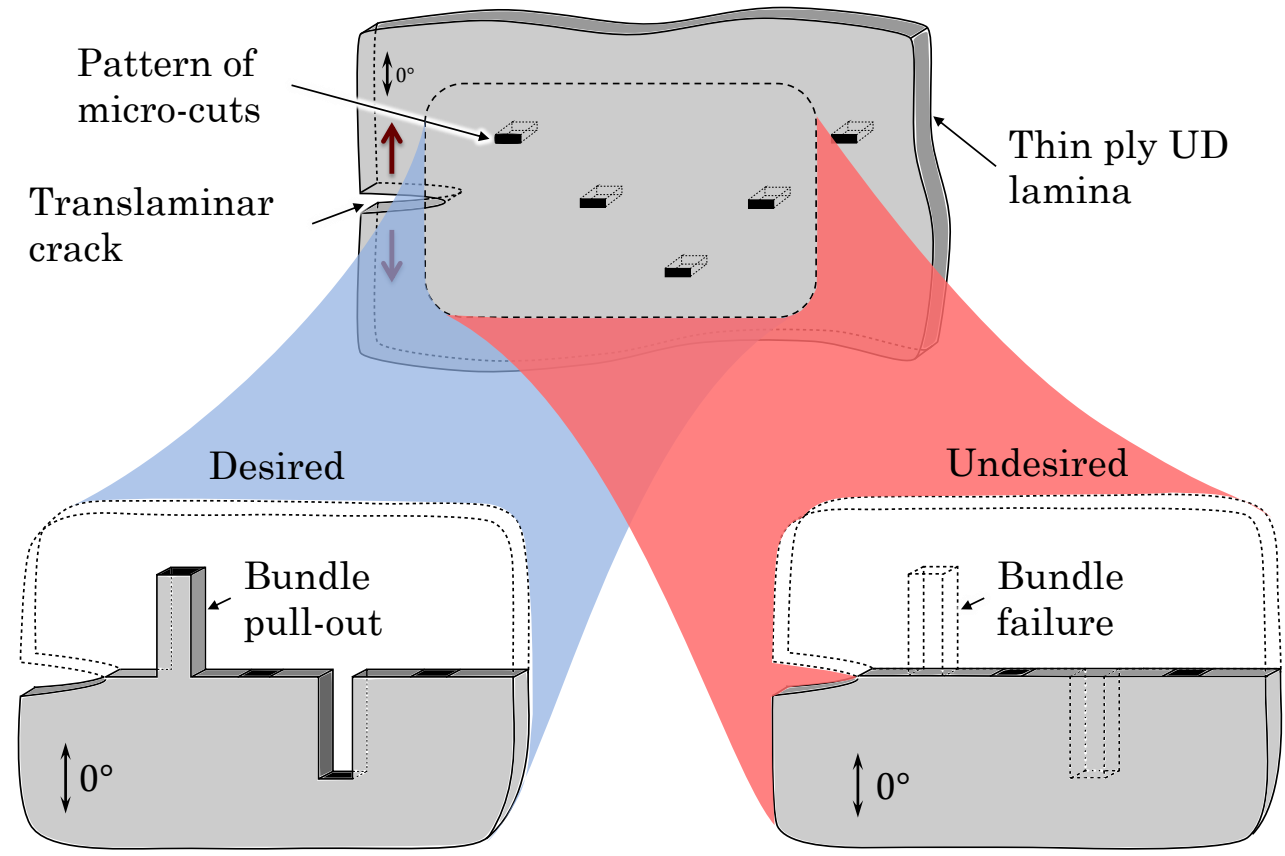

(b)

(c)

Figure 1: Crack propagation in a CFRP lamina with pattern of micro-cuts perpendicular to the fibre direction: (a) before crack propagation, (b) after crack propagation with bundle pull-out, (c) after crack propagation with bundle failure. 


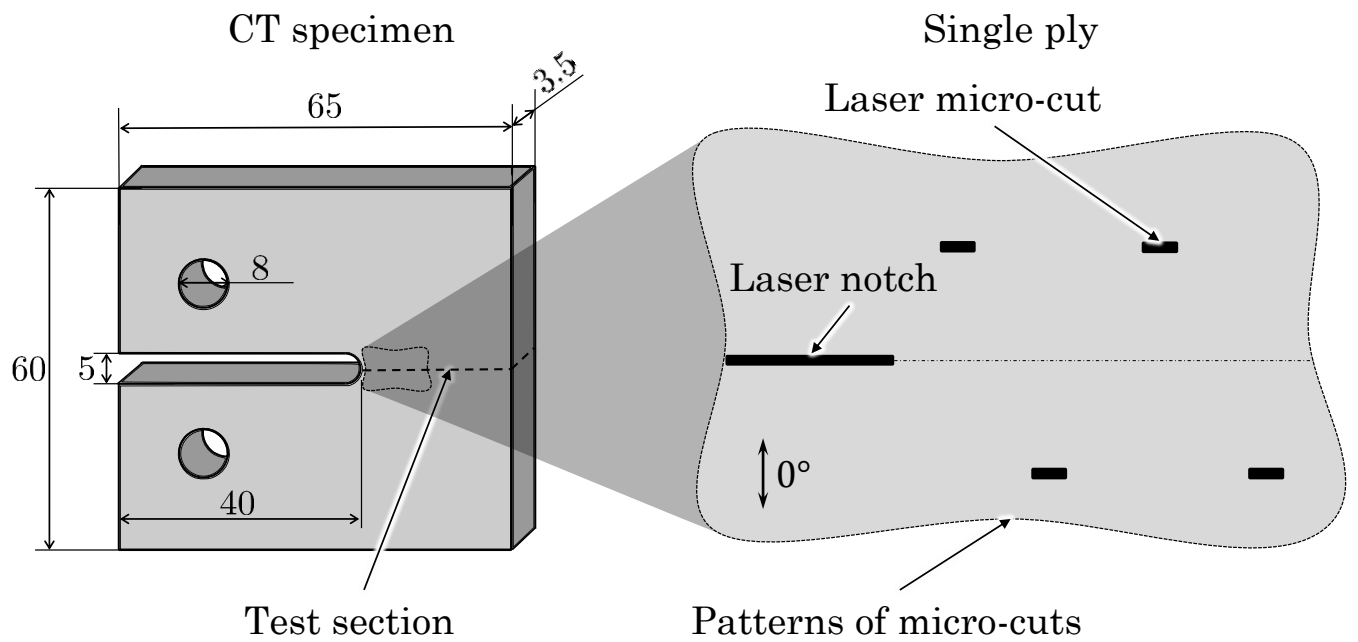

(a)

(b)

Figure 2: (a) CT specimen geometry (nominal dimensions in $\mathrm{mm}$ ) (b) Schematic representation of the pattern of micro-cuts. 


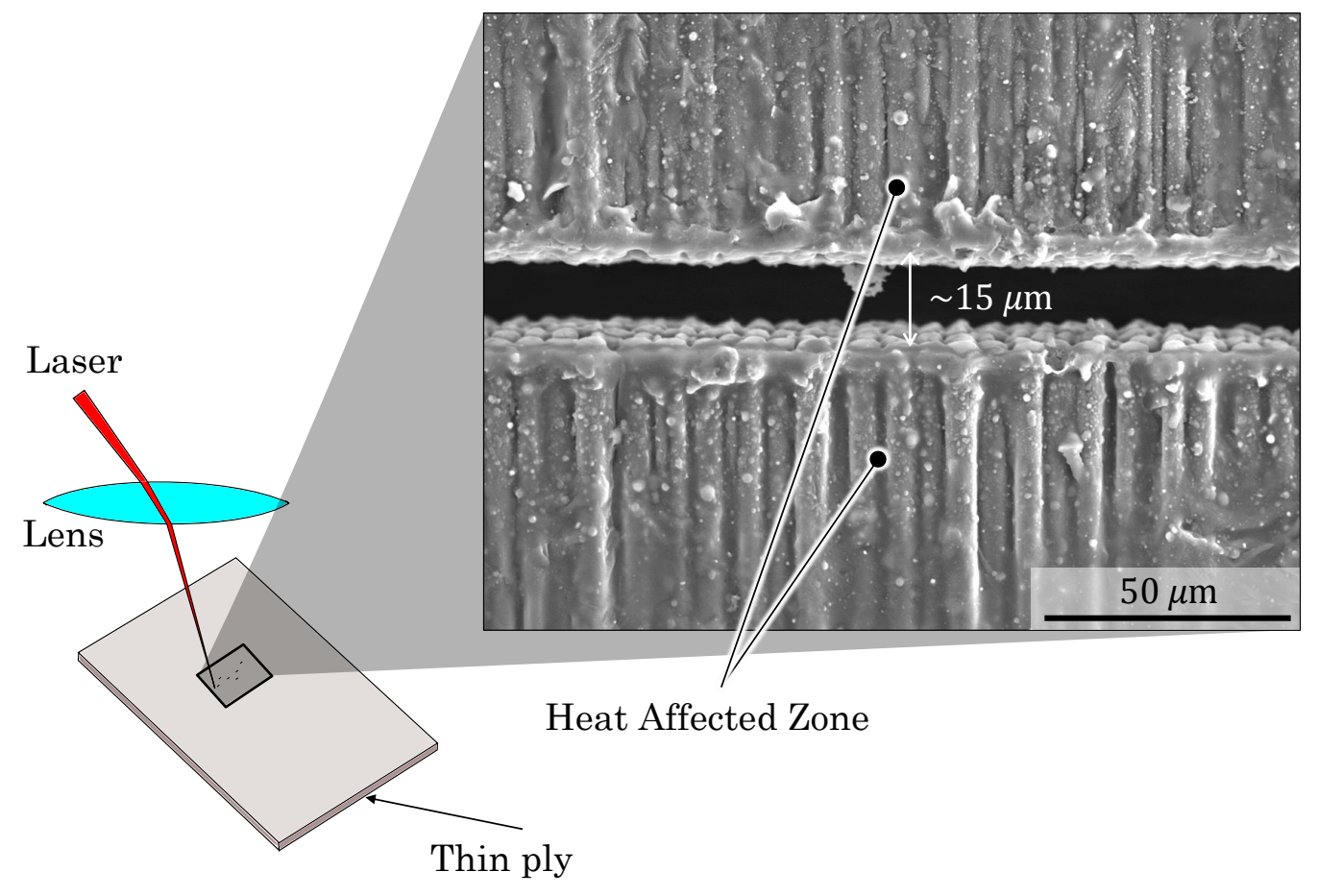

Figure 3: SEM micrograph of laser engraved micro-cut in a thin-ply composite 

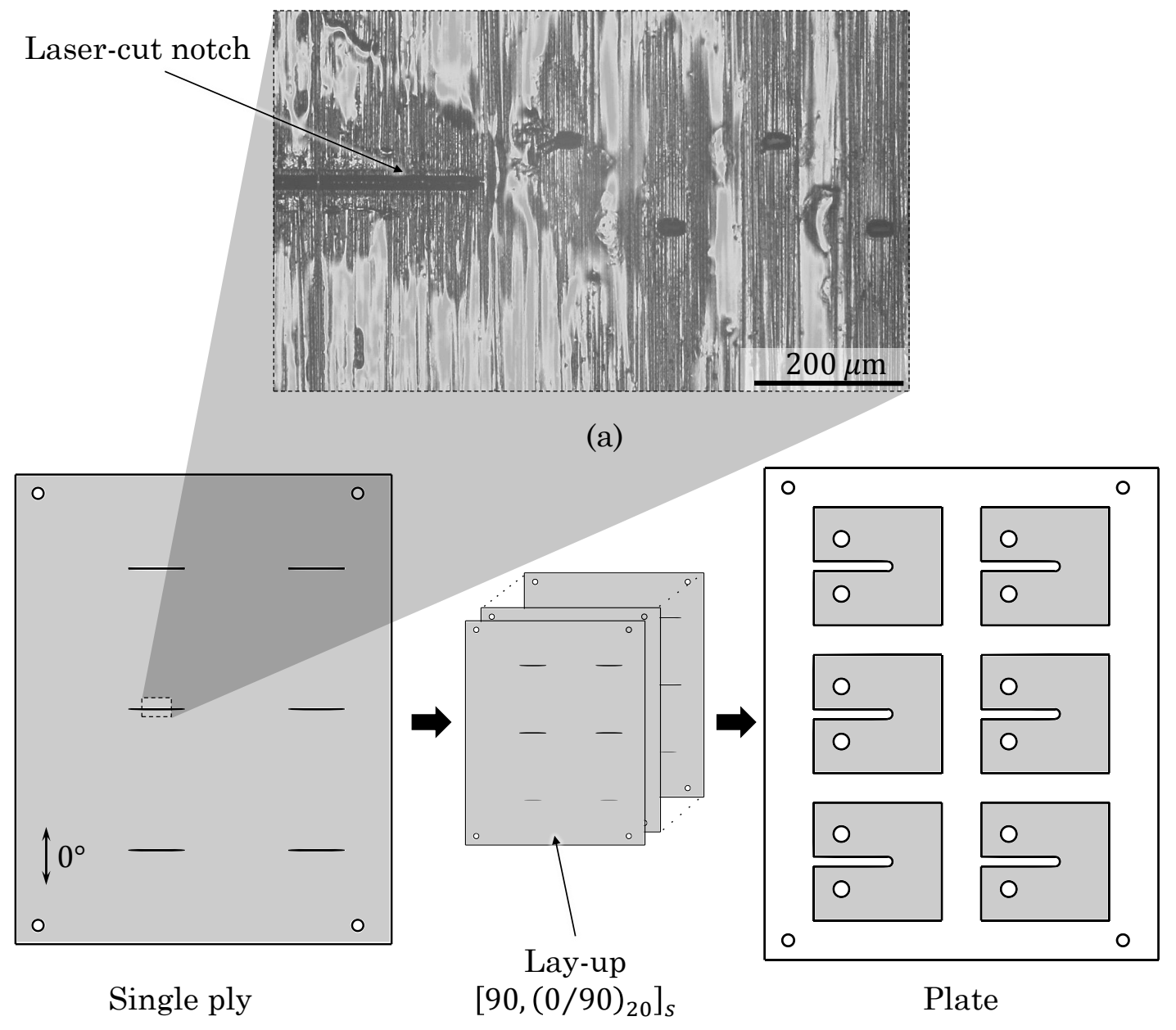

(b)

(c)

(d)

Figure 4: Representation of the laser engraving process and lay-up process: (a) detail of the laser engraved pattern, (b) single ply, (c) lay-up process, (d) specimens cut out of the final laminate. 


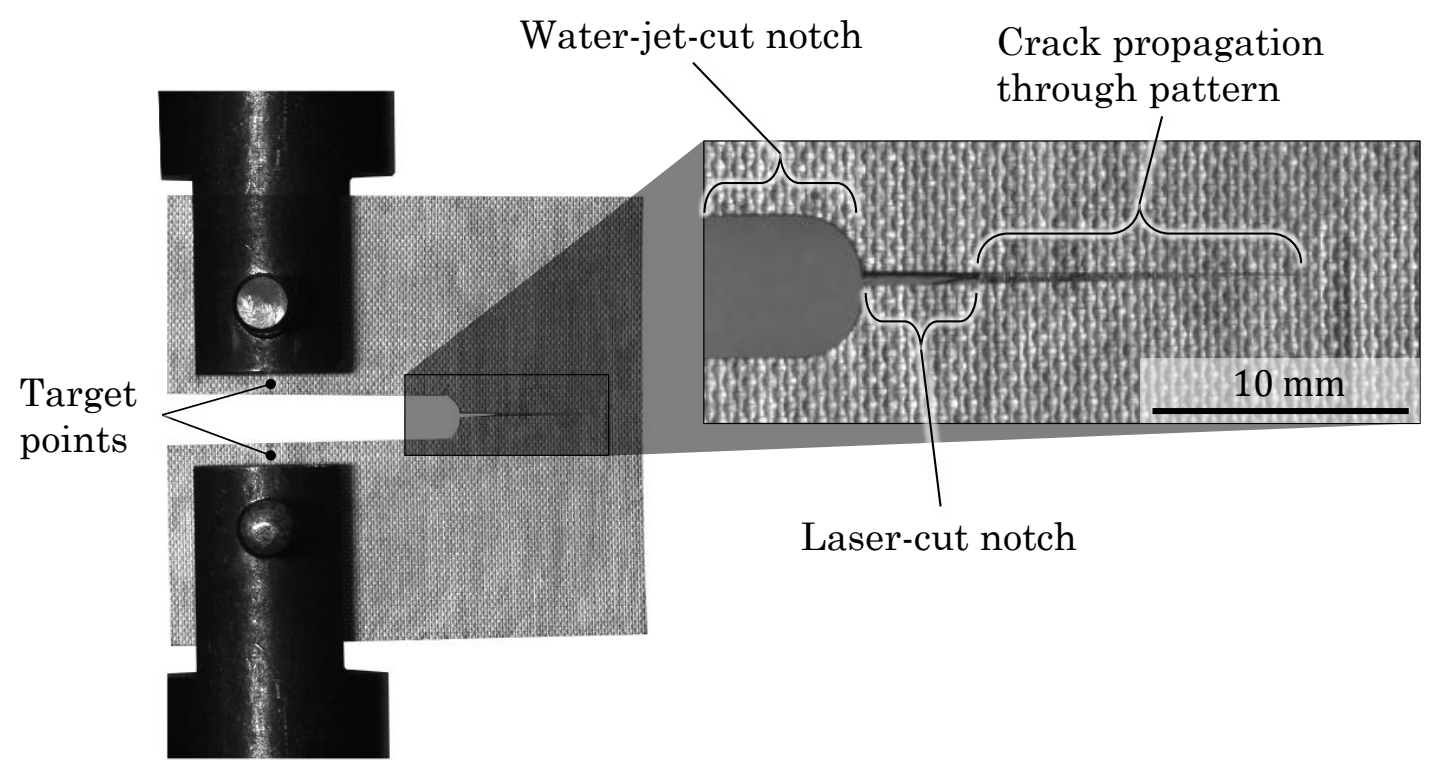

Figure 5: Tensile test of CT specimens; the magnification on the right side of the figure shows how the laser-cut notch acts as crack initiator. 


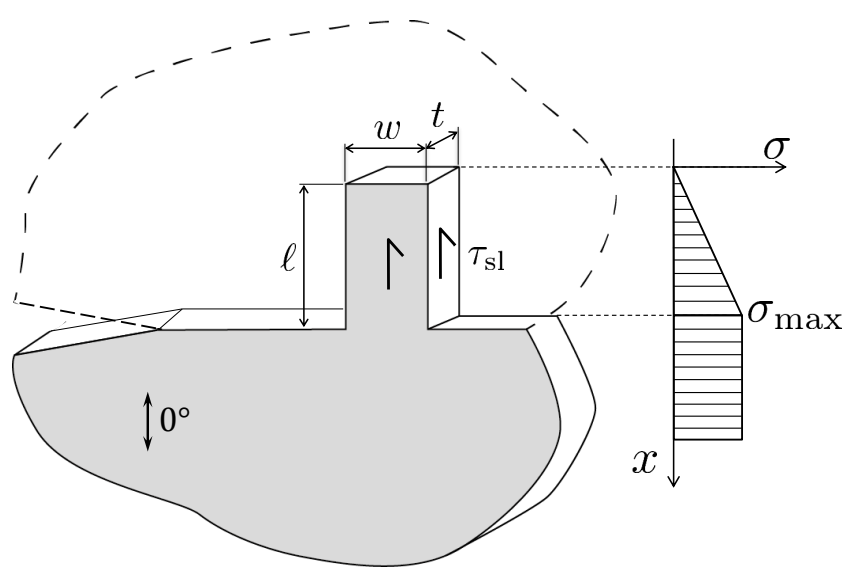

Figure 6: Tensile stress profile in bundle of fibres during translaminar crack propagation. 


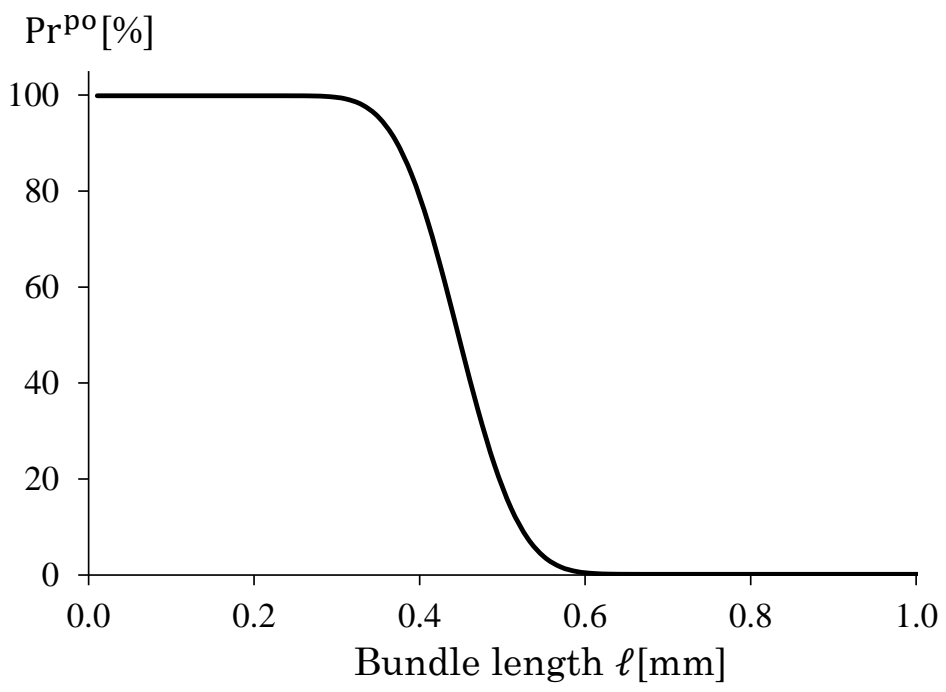

Figure 7: Analytical probability of bundle pull-out as a function of the bundle length. 


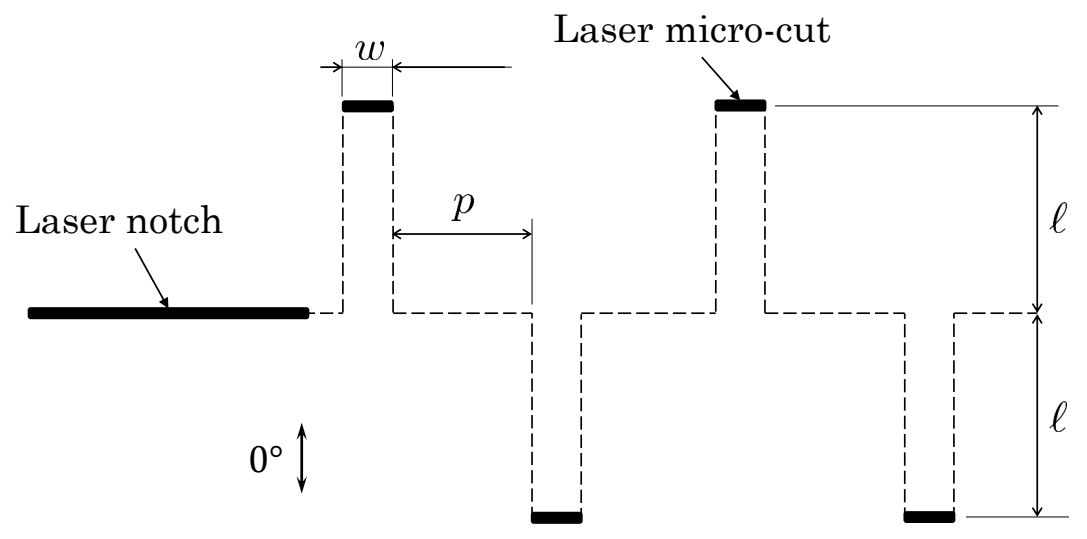

Figure 8: Design of the pattern of micro-cuts used in the parametric study 


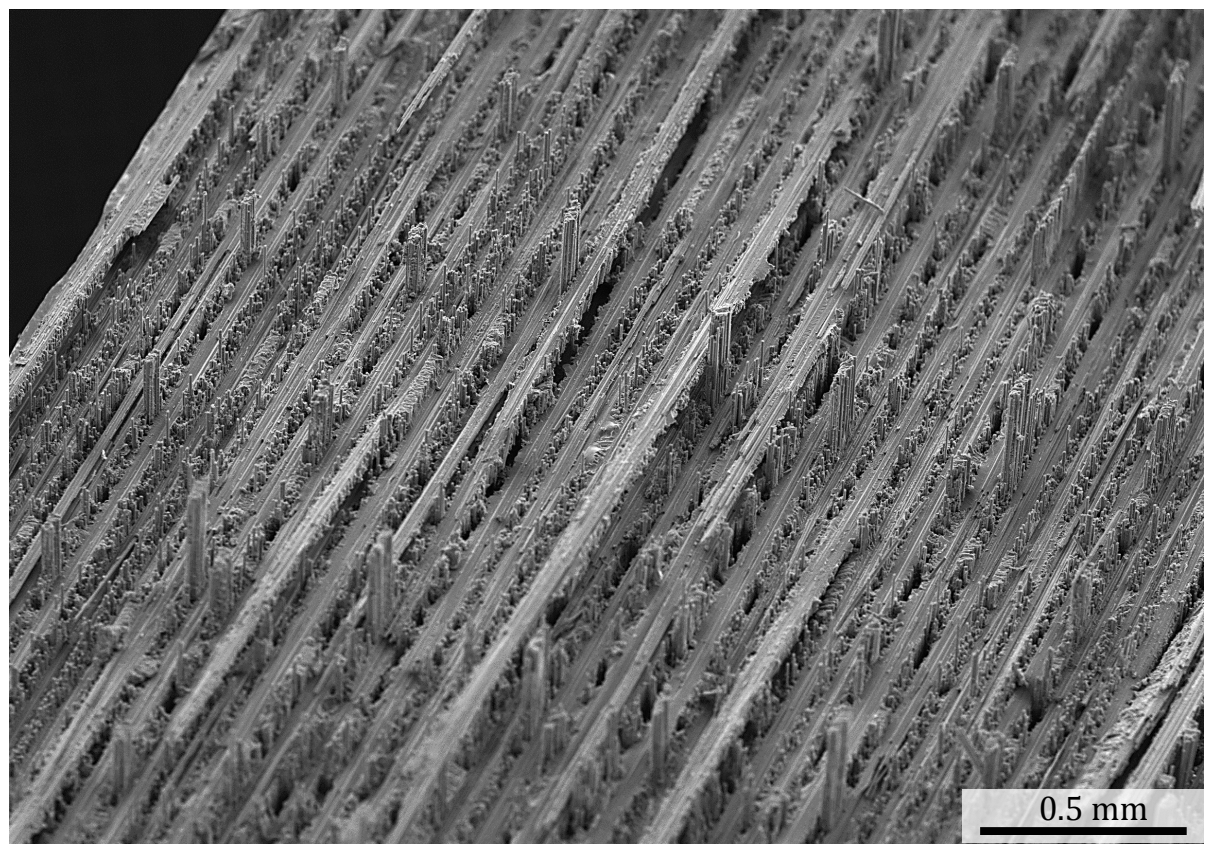

(a)

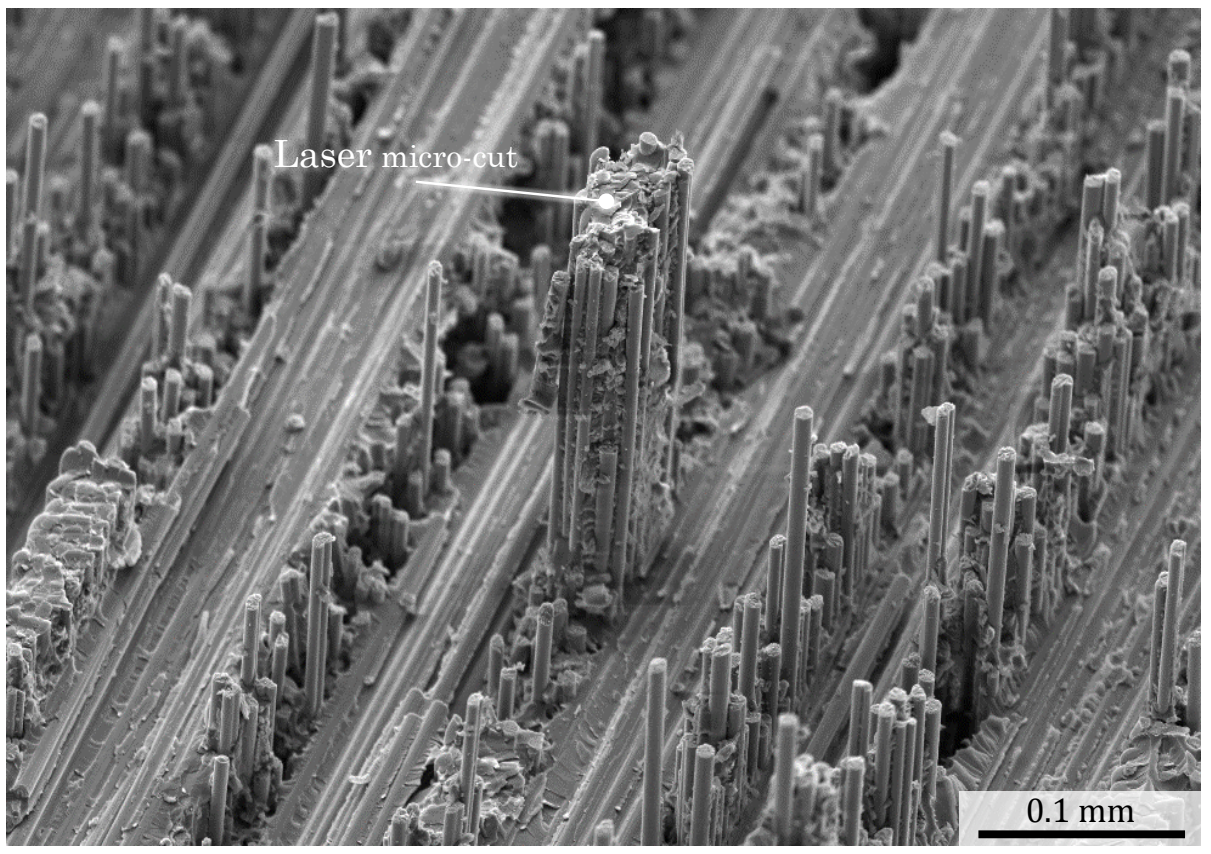

(b)

Figure 9: SEM micrograph of fracture surfaces obtained during experimental parametric study: (a) fracture surface of specimen SP1 away from the laser notch. The $90^{\circ}$ plies are characterized by a relatively uniform fracture surface with few fibre fractures. The $0^{\circ}$ plies are characterized by large bundle pull-outs in correspondence to the laser micro-cuts; (b) magnification of a large bundle pull-out protruding from $0^{\circ}$ ply; it is possible to see the laser-cut region on the top surface of the bundle. 


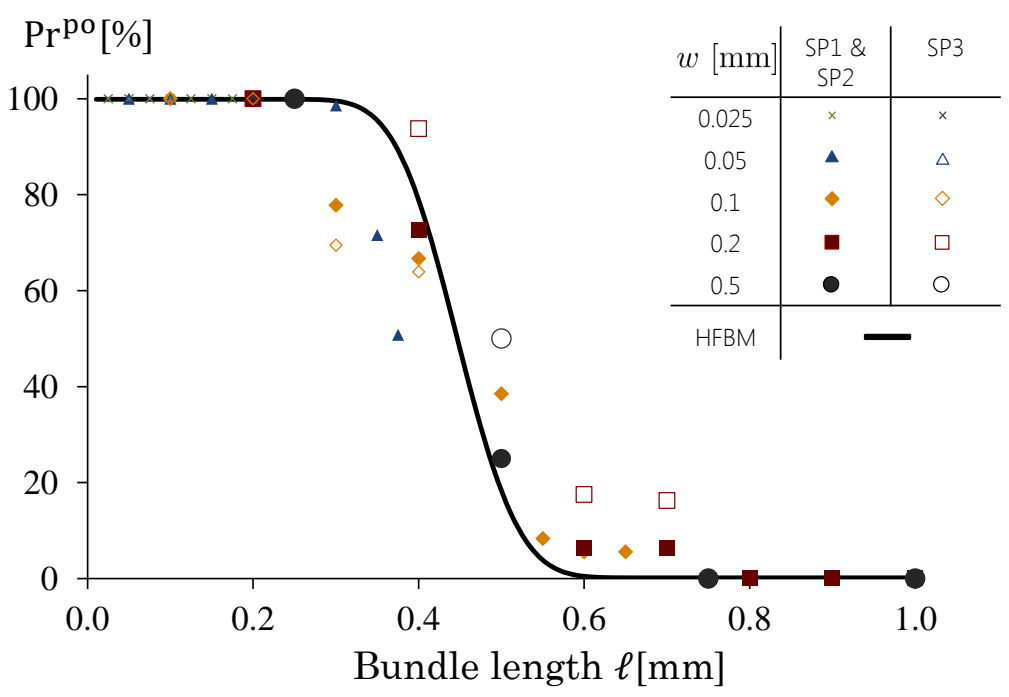

Figure 10: Experimental probability of bundle pull-out; the data points are obtained through statistical analysis of the fracture surface. The analytical probability of bundle pull-out for $w \geq t$ is plotted for comparison. 


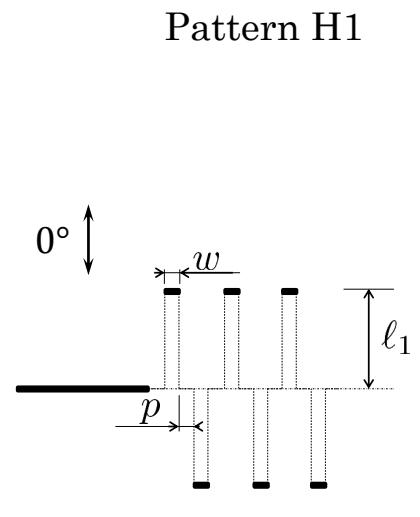

(a)

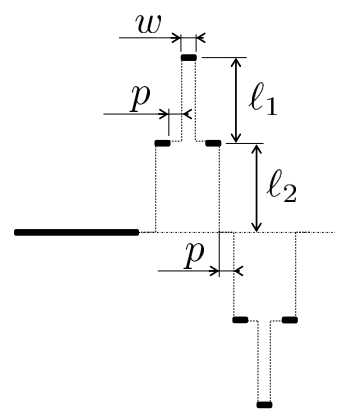

(b)
Pattern H3

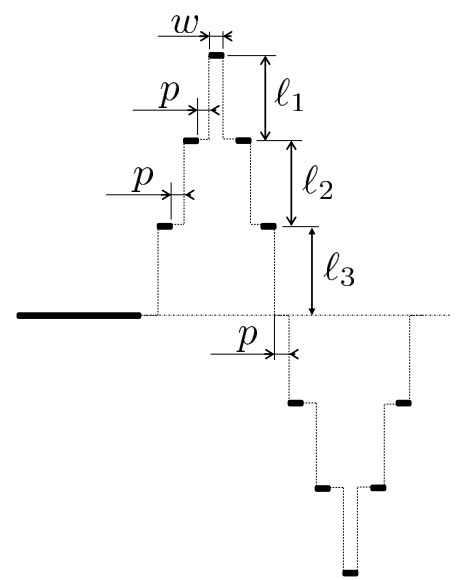

(c)

Figure 11: Hierarchical patterns of micro-cuts (thick-lines), and the correspondent pull-out structures which are expected to form during translaminar fracture (thin-lines): (a) one level of hierarchy; (b) two levels of hierarchy; (c) three levels of hierarchy. 


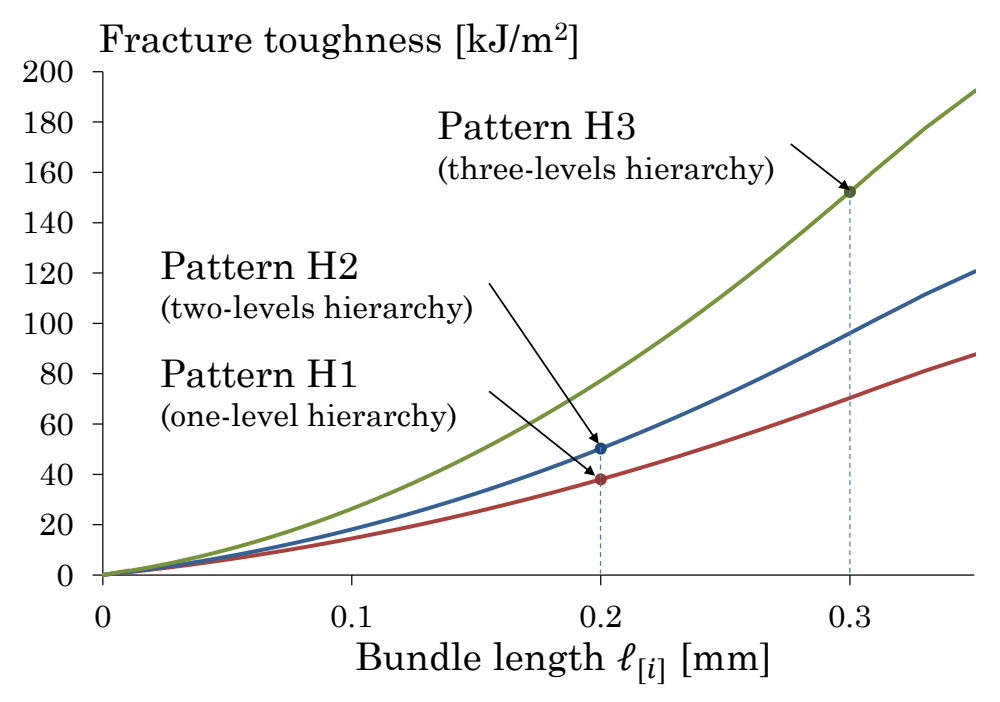

Figure 12: Translaminar fracture toughness as function of the bundle length for the three hierarchical patterns as predicted by the present model. 


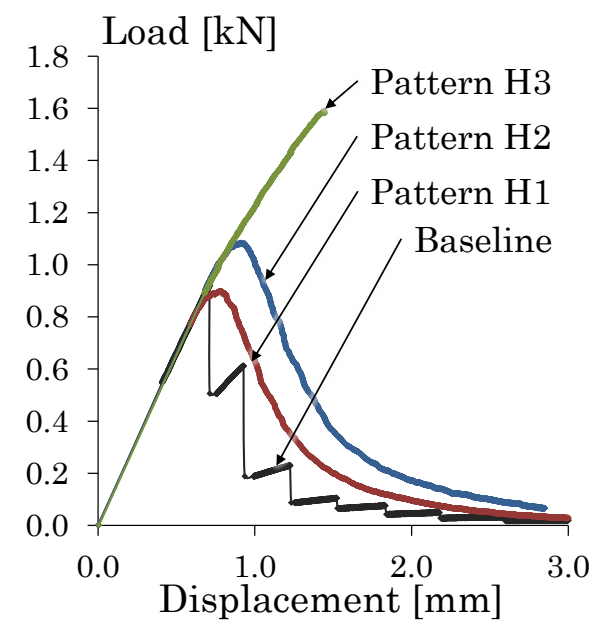

(a)

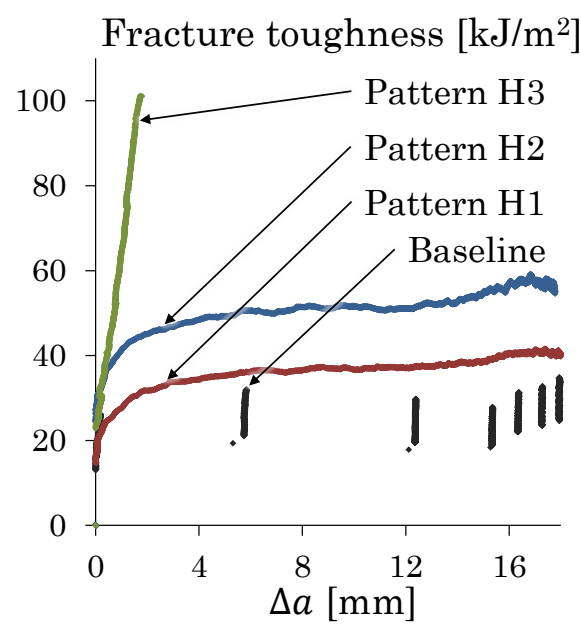

(b)

Figure 13: Test data for the four CT specimens: one made of the baseline thin-ply composite without any modification and the other three containing hierarchical patterns of micro-cuts: (a) Load vs. opening displacement; (b) Fracture toughness of the $0^{\circ}$ plies vs. crack length. 


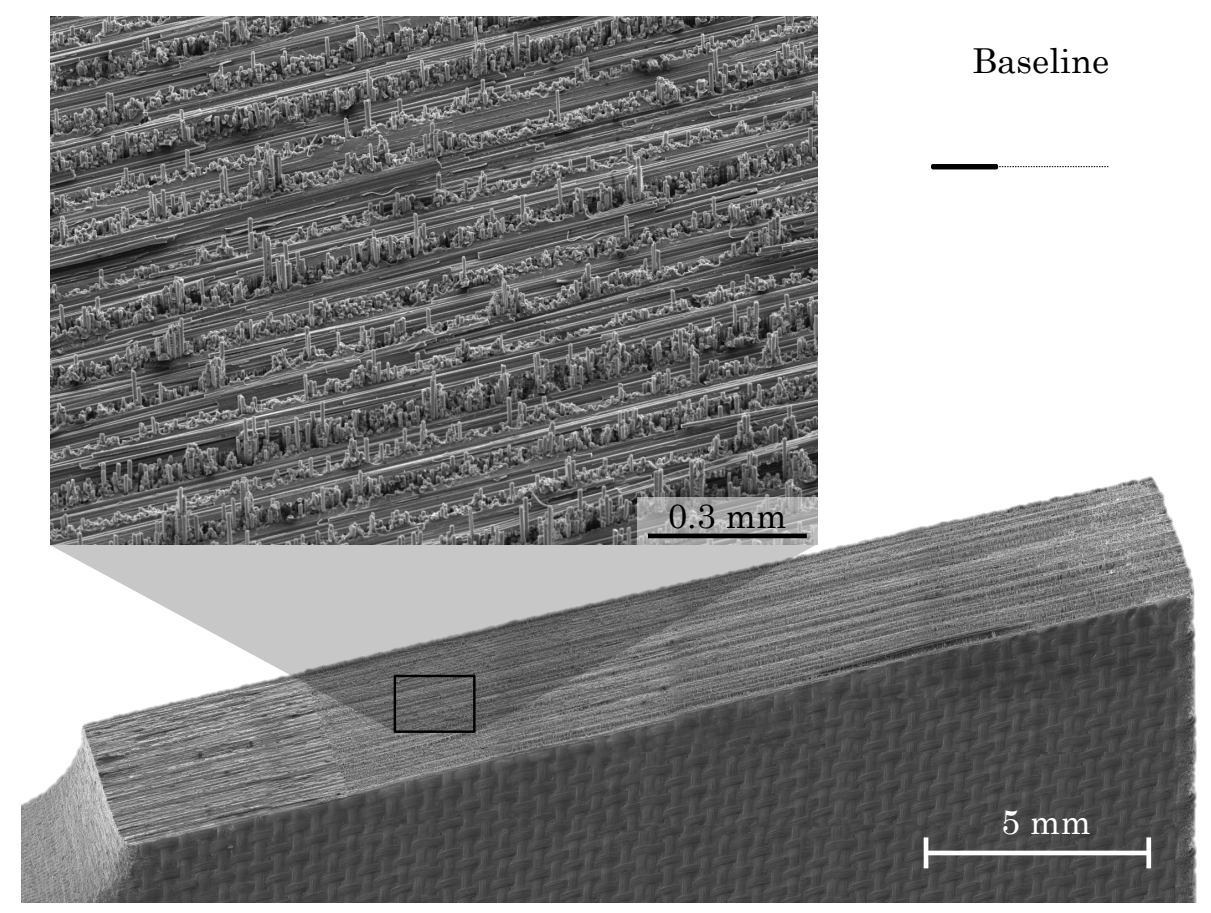

(a)

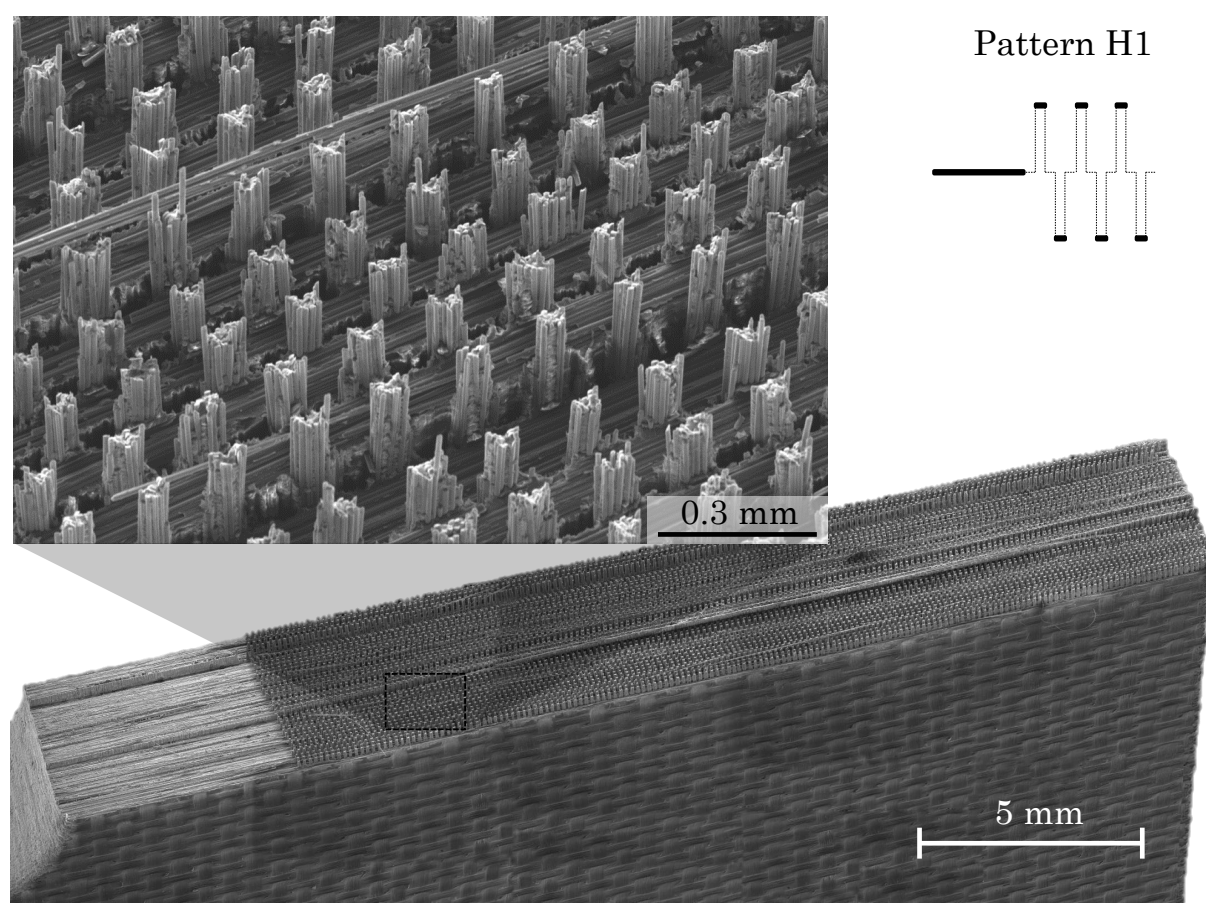

(b) 


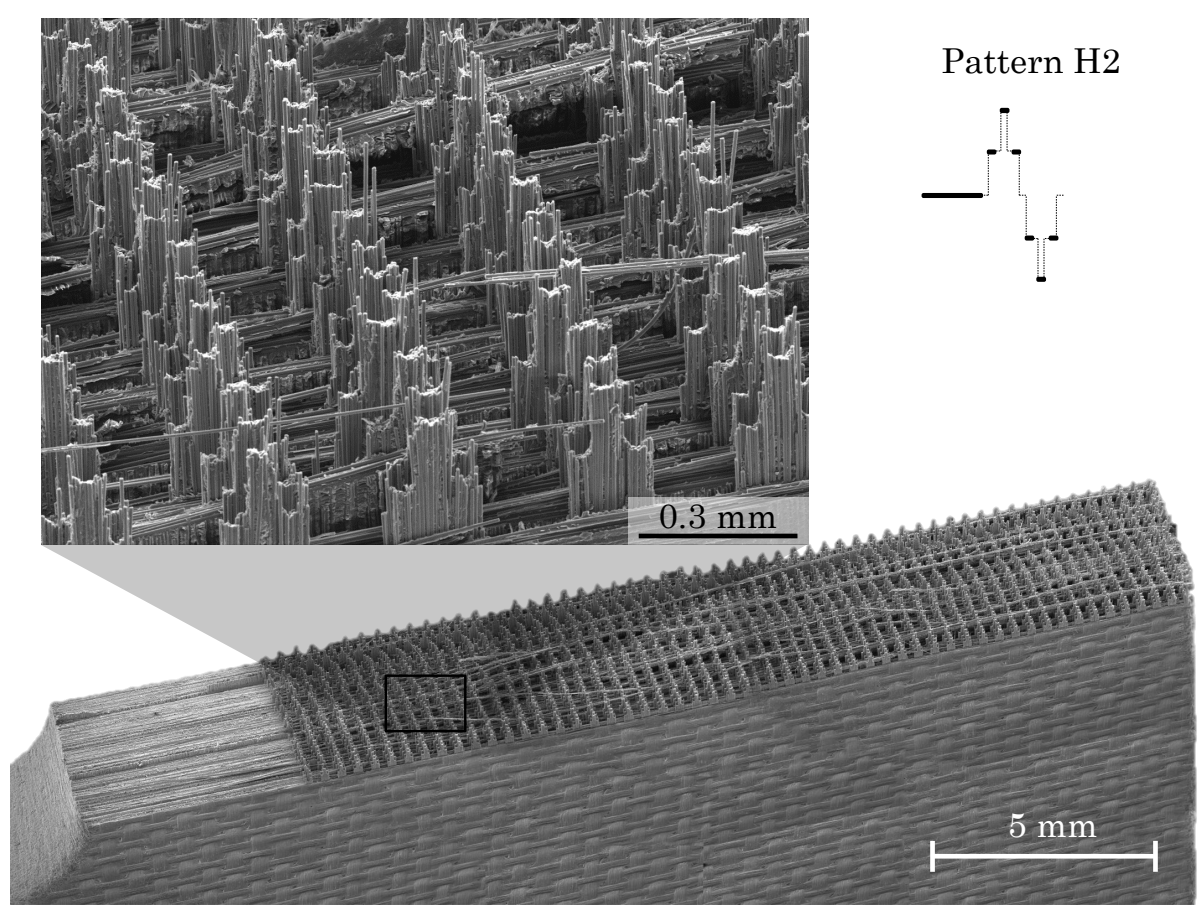

(c)

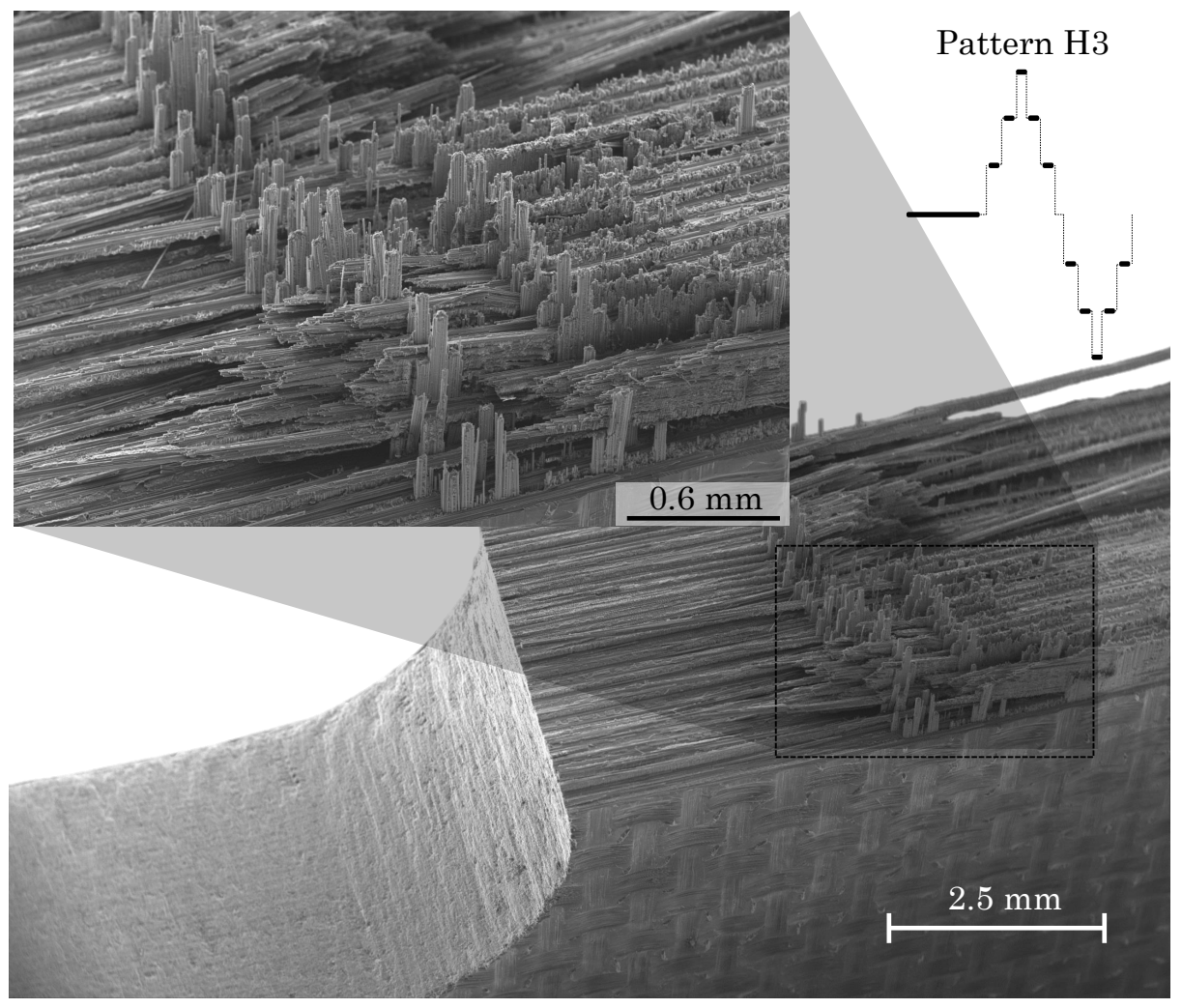

(d)

Figure 14: SEM micrograph of fracture surfaces obtained during toughness measurements for the hierarchical pattern: (a) baseline material without any micro-cut; (b) hierarchical micro-cuts with one level of hierarchy; (c) hierarchical micro-cuts with two levels of hierarchy; (d) hierarchical micro-cuts with three levels of hierarchy. 


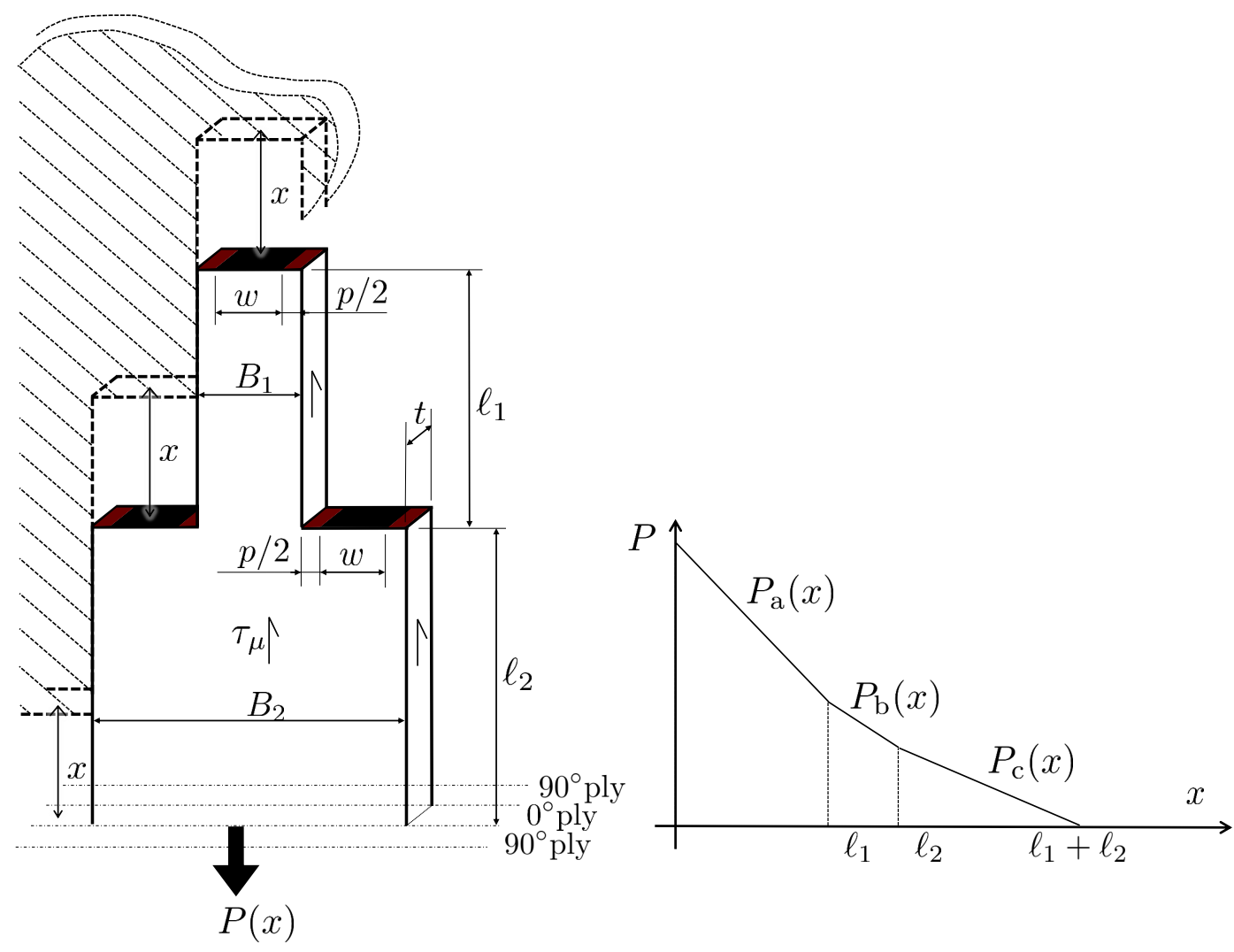

Figure 15: Schematic representation of single bundle pull-out for hierarchical pattern with two levels of hierarchy; the graph on the right side shows the force $P$ necessary to pull the bundle out of the the fracture surface. 


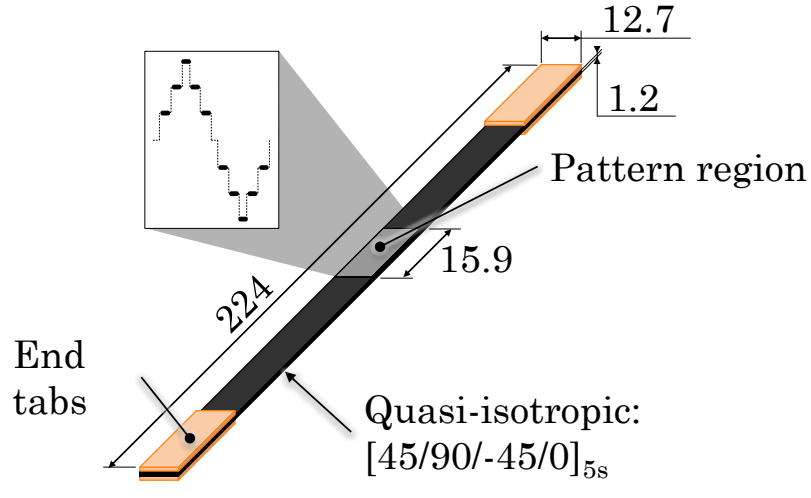

(a)

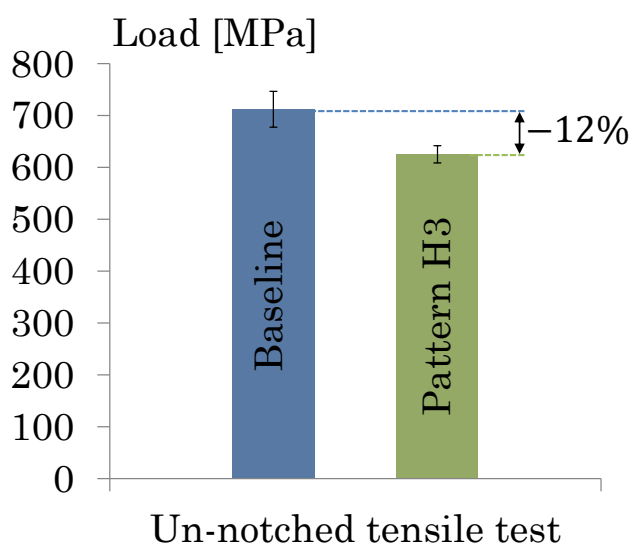

(b)

Figure 16: (a) Un-notched tensile specimen geometry (nominal dimensions in $\mathrm{mm}$ ) with schematic representation of the pattern of micro-cuts H3; the pattern is always perpendicular to the fibre direction and is repeated uniformly over the entire pattern region for each ply in the laminate. (b) Average tensile strength and standard deviation for baseline material and material with pattern $\mathrm{H} 3$ (five specimens were tested for each configuration). 